\title{
Natural quantitative genetic variation in seed size, dormancy, and seedling vigor in upland and lowland ecotypes of a $\mathrm{C} 4$ perennial
} grass

\author{
Samsad Razzaque ${ }^{1}$ and Thomas Juenger ${ }^{1}$ \\ ${ }^{1}$ The University of Texas at Austin
}

October 8, 2020

\begin{abstract}
Understanding the environmental drivers and the genetic architecture of traits involved in local adaptation is of fundamental interest as it may give insight to ecological speciation. Unfortunately, local adaptation studies rarely consider early life stages. As a result, we know surprisingly little about the genetic architecture and evolution of seed-based life history traits especially considering adaptation to xeric and mesic habitats. Here, we evaluate the genetic architecture of seed trait divergence in a recombinant inbred population derived from xeric and mesic ecotypes of Panicum hallii. We found the majority of seed related QTL had overlapping intervals, suggesting tight linkage and possibly pleiotropy are important in seed trait evolution. Our results suggest that the evolution of these traits is non-independent and may involve tradeoffs that affect the direction of divergence. Seed size and germination rate shared two colocalized QTL, each with antagonistic additive effects. This supports the hypothesis of a functional genetic trade-off between these two traits, resulting in either large seed/high dormancy or small seed/low dormancy trait combinations. We identified several candidate genes that may explain this trade-off. Overall, our study provides insights into the factors facilitating and potentially constraining ecotypic differentiation in plants through seed-based life history traits.
\end{abstract}

Keywords: seed size, dormancy, quantitative genetics, recombinant inbred line, QTL, Panicum hallii

\section{Introduction}

Local adaptation is an important component of responses to changing environments, as it reveals how environmental variation can drive phenotypic and genetic differentiation as a response to selection (Davis and Shaw 2001; Conover et al. 2009). In this process, plant populations may be selected for different resource allocation strategies based on habitat structure or climatic features in a region of the species range. Theory suggests a key trade-off in resource allocation is between the quantity and quality of offspring. For example, alternative reproductive strategies might allocate resources to fewer large seeds versus many small seed in response to heterogeneity in the amount or predictability of rainfall (Smith and Fretwell 1974; Daws et al. 2007). These trade-offs may maintain genetic variation among populations and drive phenotypic partitions within species (Futuyma and Moreno 1988; Jasmin and Kassen 2007). In plants, soil water availability plays a vital role maintaining global species distribution and determining genetic and phenotypic differences within species range (Stebbins Jr 1952; Whittaker 1970; Woodward et al. 2004). Thus, plants adapted to habitats differing in soil water availability can drive the evolution of divergence and may promote ecological speciation (Baker 1972; Roux et al. 2006; Juenger 2013; Rundle and Nosil 2005).

Plants are sessile organisms with limited mobility, with dispersal occurring primarily at the seed stage. This makes the seed stage a crucial one in the life history of plant species. Seed mass is a key component of 
adaptation in plants, as this trait connects the ecology of reproductive strategies with dormancy, seedling establishment and vegetative growth (Grime et al. 2014; Shipley et al. 1989; Leishman and Westoby 1992; Rees 1996). Plants adapted to xeric habitats tend to have larger seeds compared to those occurring in mesic habitats (Baker 1972). A strategy producing fewer large seeds might ensure successful establishment by generating vigorous seedling growth, perhaps timed with pulses of seasonal precipitation. In contrast, a strategy producing many small seeds might arise in environments with highly predictable patterns of rainfall or where establishment and success are limited by other resources. Several studies have shown a positive correlation with seed mass and seedling root and shoot growth in different species (Jurado and Westoby 1992; Lloret et al. 1999; Wulff 1986). Seed dormancy is also another trait tightly linked to seed mass. A central idea is that dormancy is a bet-hedging approach to reproduction in an unpredictable and heterogeneous environment (Venable 2007; Childs et al. 2010). In systems with strong dormancy, specific environmental conditions must occur to break dormancy but also to ensure germination after dormancy is broken (Baskin and Baskin 1998). While seed and early life stages are critical in plant biology, we know surprisingly little about their genetic basis or their role in local adaptation (Donohue et al. 2010; Donohue 2014). For example, field experiments with plants are typically based on the transplantation of seedlings (Lowry and Willis 2010a; Anderson et al. 2013; Ågren et al. 2013; Fournier-Level et al. 2013) and hence do not measure the significance of likely adaptive differentiation and genetic tradeoffs expressed at the seed and germination stage.

Seed mass and dormancy exhibit considerable phenotypic variation in nature (Bradford and Nonogaki 2008; Baker 1972; Harel et al. 2011; Lacerda et al. 2004; Bentsink et al. 2010). This variation might result from phenotypic plasticity or genetic differentiations within a species. Based on the habitat and seed size correlations, patterns in nature suggest seed size evolution is adaptative and is under stabilizing selection. These conclusions are mostly based on evidence from experiments with crop plants grown in controlled environments (Silvertown 1989). Studies with wild plants often show marked phenotypic plasticity and low heritability of seed size (Stanton 1984; Primack and Antonovics 1981). An analysis of reciprocal transplant experiments can measure the frequency and magnitude of plasticity related to adaptation of populations and phenotypic variation within species (De Jong 2005). If the variation is not plastic and instead caused by genetic differentiation, then exploring genes underlying this natural variation would help understand the evolutionary forces driving seed size related phenotypic variation in natural populations. It also helps to understand how adaptive evolution shaped genetic variability for these traits.

To explore the genetic basis of variation in complex traits, a common approach is the use of whole genome scans to identify quantitative trait loci (QTLs) (Falconer and Mackay 1996; Kearsey 1998; Lynch and Walsh 1998). QTL mapping studies estimate several genetic parameters underlying phenotypic variation including loci numbers, the type and magnitude of QTL effects, detection of loci with pleiotropic effects, and interaction between genes and gene-by-environment interactions when tested in different environments (Prioul et al. 1997; Lowry et al. 2019; Lowry et al. 2015). A genetic trade-off between traits can be inferred in QTL study when the additive effects of a pleiotropic QTL show antagonistic direction of effects relative to the direction of selection for traits (Dechaine et al. 2014; Xiao et al. 1998; Agrawal et al. 2010). Although these trait covariances are likely important drivers of plant adaptation, very little is known about the genetic architecture of such trait complexes. For example, an unresolved question is whether seed mass variation and dormancy jointly evolve by common pleiotropic effects, or if these traits evolve independently.

Seed size QTL studies have been conducted mainly in domesticated species (e.g., rice, maize) (Grandillo and Tanksley 1996; Lu et al. 1997; Maughan et al. 1996; Mian et al. 1996; Paterson et al. 1995; Rami et al. 1998; Timmerman-Vaughan et al. 1996; Xiao et al. 1996). Several genes and pathways have been identified through QTL studies that cause seed size variation. For example, positional cloning of a seed mass QTL in rice identified the DEP1 gene which encodes a noncanonical G protein subunit. A recent study shows that $D E P 1$ overexpression promotes large seed growth, whereas downregulation or knockouts of DEP1 result in small grains and straight panicles (Sun et al. 2018). In addition, many seed dormancy QTLs have been identified in crops and the model plant Arabidopsis (Bentsink et al. 2007). Delay of Germination 1 (DOG1 ) was discovered as an Arabidopsis QTL with the Cape Verde Island (Cvi) allele leading to exceptional 
dormancy relative to the Landsberg (Ler ) allele (Alonso-Blanco et al. 2003; Bentsink et al. 2010). DOG1 is the only cloned gene for a naturally variable dormancy trait (Bentsink et al. 2006) and also colocalizes with QTL for germination timing and fitness in the field (Huang et al. 2010). However, most of the seed mass and dormancy gene discovery has occurred in domesticated and model species and it's unknown if the same genes will be discovered in in natural populations.

Here, we estimate the environmental and genetic variability for seed traits, dormancy, and early growth in Panicum hallii ecotypes using quantitative genetic approaches. We identify genomic regions controlling these traits using QTL mapping methods, which allow us to explore their genetic architecture and to test for genetic constraints and tradeoffs impacting seed evolution. In this study, we used a recombinant inbred line (RIL) population generated from upland and lowland ecotypes of $P$. hallii. This is a self-fertilizing C4 grass species, mostly distributed across the southwestern part of the US and northern Mexico (Smeins et al. 1976; Waller 1976; Hatch et al. 1999; Lovell et al. 2018b; Gould et al. 2018). It has considerable population genetic structure in natural populations and also between major biogeographical regions (Lowry et al. 2013; Palacio Mejia 2018). However, the greatest differentiation within P. hallii occurs between ecotypes adapted to lowland/coastal and upland/southwestern regions. These two ecotypes are P. hallii var. hallii and P. hallii var. filipes. $P$. hallii var halliiis the more widespread ecotype and occurs primarily in xeric upland calcareous soils whereas filipes is located primarily in mesic and seasonal wet areas (Lovell et al. 2018a).

In our study, we specifically addressed the following major questions: (i) Do seed traits exhibit phenotypic plasticity in response to xeric and mesic habitat variation? If so, is there genetic variation in plastic responses as indicated by genotype-by-environment interactions? (ii) What is the genetic architecture underlying seed size, dormancy and seedling growth traits among var. hallii and var. filipes ? (iii) Do QTLs for these traits colocalize in particular chromosomal regions? Are there QTL hotspot for ecotype differentiating traits? (iv) Is there evidence for seed size/dormancy trade-offs based on patterns of pleiotropic QTL? (v) Can candidate genes for seed traits be identified by differences in gene expression between ecotypes with divergent seed phenotypes? We found little trait plasticity and strong genetic differentiation and an overall polygenic genetic architecture of seed traits in Panicum hallii. We discovered a number of genomic QTL clusters associating seed mass and germination traits. Our molecular work identified considerable gene expression divergence in seeds between ecotypes, including at a number of strong candidate genes occurring in QTL intervals. Together, these results provide insight in possible avenues of local adaptation mediated by seed traits and point to possible candidate genes for future investigation.

\section{Materials \& Methods}

\section{Plant materials, linkage map and reciprocal transplantation}

We reciprocally transplanted both parental lines at their lowland (Nueces Delta Preserve, Odem Texas) and upland natural habitats in the field (Breckenridge Field Lab, Austin, Texas) to evaluate seed trait plasticity. The Austin site represents typical upland halliihabitat with dryer and shallower soil, where the Odem site represents the lowland filipes coastal habitat. We inspected the habitat area first and chose a place for our experimental planting with naturally occurring P.hallii . We geminated seedlings in one-inch pots in a greenhouse located in University of Texas, Austin and grew them to 20 days of age. For plant material we picked two representative genotypes of the upland and lowland ecotypes (HAL2 andFIL2 , respectively), that have been used in earlier genome efforts (Lovell et al. 2019). We transferred 300 seedlings to the field sites in Fall 2018 ( 75 uplands +75 lowlands $=150 \times 2$ sites $=300)$.). After transplanting, we did not water or fertilize them but visited both sites in 30-day intervals until November 2018, when we collected seeds from both sites. We later randomly picked ten plants from each genotype to measure seed mass and dormancy. In total, we measured 40 seed lots (two genotype $\mathrm{x}$ two locations $\mathrm{x}$ ten replicates) for this part of the study. Seed mass was calculated by weighing 100 seeds per line using an analytical balance (Mettler Toledo, Columbus, Ohio, USA). Then, we established a germination assay in a lab growth chamber with 15 seeds per petri-dishes (unit of replication, total 40 petri-dishes). We later calculated germination rate for these lines. 
Because we constantly observed strong seed dormancy in halliiecotype, we wanted to make sure the dormancy in hallii is not because of the inviable/sterile seeds. Several ways have been tested to break dormancy in different species (Kimura et al. 2015). In P. hallii we applied scarification technique and found be effective for breaking dormancy in the upland hallii ecotype. We examined all non-germinated seeds from this germination assay to evaluate viability and dormancy by forcing germination after removing seed coats. We removed the seed coat by gently using sandpaper (P100) and then germinated them following the protocol mentioned in the following method section.

\section{Plant Material for Genetic Mapping}

We used a recombinant inbred population (RIL) generated from an upland (hallii) and lowland (filipes ) parental genotypes representing ecotypes of $P$. hallii . The upland (hallii; HAL2) parent was collected from the Lady Bird Johnson Wildflower Center, Austin, Texas $\left(30.16^{\circ} \mathrm{N}, 97.87^{\circ} \mathrm{W}\right)$ and the lowland parent (filipes; FIL2 ) was collected from an area near the coastal city of Corpus Christi, Texas $\left(27.65^{\circ} \mathrm{N}, 97.40^{\circ} \mathrm{W}\right)$. Upland hallii was used as the maternal seed parent. The RIL population was generated following a single seed descent method from $\mathrm{F}_{2}$ progeny of a single $\mathrm{F}_{1}$ hybrid to the $\mathrm{F} 7$ generation. A total of 335 RILs were re-sequenced up to 30x coverage and used to build a high-density linkage map after mapping against filipes reference genome. The final map consists of 722 markers in 9 chromosomes. A detailed description of the development of RIL population and the genetic map construction are discussed in Khasanova et al. (2019).

\section{RIL Seed materials and experimental setup}

We collected seeds from 335 RIL and their two parental lines from well-watered plants grown in a field experiment at the Brackenridge Field Laboratory, Austin, Texas in September 2016. RIL seeds were collected from three maternal parents, and parental lines were collected from 6 maternal parents from the field. We carefully separated good seed from chaff, detritus, or undeveloped seeds and kept them at room temperature in coin envelopes for 6 months before starting the experiment trials.

We utilized a large walk-in growth chamber experiment to control environmental conditions throughout the experimental trials. Growth chamber temperature was set at $28^{\circ} \mathrm{C}$ during light and $22^{\circ} \mathrm{C}$ during dark conditions, and the photoperiod for the chamber was set at $12 \mathrm{hrs} \mathrm{light} / 12 \mathrm{hrs}$ dark. Seeds were germinated in petri dishes $(25 \times 100 \mathrm{~mm})$ with sterilized sand. We used $60 \mathrm{gm}$ of sands for each petri dish and added $13 \mathrm{ml}$ tap water to each dish. Water was sprayed on the upper lid of the petri dishes to keep the inner environment moist and each dish was sealed with parafilm. The experiment was replicated across three temporal blocks in which each block contained a single petri dish (our unit of replication) of each genetic line. In each petri dish, 15 seeds per lines were used. The complete experimental design was as follows: 335 RILs + six petri dishes of hallii (upland parent) + six petri dishes of filipes (Lowland parent)] x three replication $=1041$ petri dishes of seedling plants.

\section{Seed mass \& shape}

We weighted 100 seeds per line using an analytical balance (Mettler Toledo, Columbus, Ohio, USA) in three sets. Seed mass was calculated for each line dividing total mass by 100 (Seed weight= weight of 100 seeds / 100). Seed images were obtained using a Nikon D5600 camera with a macro lens (100 mm) including a standard metric scale ruler in each image. These images were used to analyze seed shape. Seeds were dispersed across a white paper field (15 seeds per genotype) for image capture. ImageJ (Abràmoff et al. 2004) was used to process and analyze images. All images were transformed to binary and eight seeds from each line were analyzed for seed length, width, area and seed roundness (seed roundness is the ratio of seed width and seed length).

\section{Germination timing and germination rate}

We inspected petri dishes once a day (starting at 11am) to record germination. Germination timing for each genotype was recorded as the first day that germination was observed from a petri dish. We recorded the number of germinated seedlings from every petri dishes at ten days after germination time. We calculated the germination rate as the per genotype following the equations below: 
Germination Rate $=(($ number of seedlings / 15 seeds $)$ X 100).

\section{Shoot length, root length and root shoot ratio}

We unsealed the petri dishes five days after germination and measured shoot length with a metric scale on three randomly selected seedlings per line. Then, we sprayed the upper lid of the petri dishes and resealed them with parafilm. While measuring the seedlings at five days, we marked these seedlings to identify them for subsequent measurement. Five days later, we again measured shoot and root length from the same marked seedlings (ten days after germination). From the shoot and root length, we calculated shoot/root ratio. Shoot root ratio (SRR) is expressed as the percent of shoot growth relative to root growth after ten days after germination time. It was calculated as follows: SRR $=$ Shoot Length / Root Length $* 100$.

\section{Relative growth rate and vigor index data}

Relative growth rate (RGR) was calculated from shoot length data collected from two different time points as: RGR = shoot length ten days - shoot length five days / difference of days (five days). RGR is the growth (here aboveground length) relative to the size of the plant height initially present at a given time interval. It is often a strong indicator of plant strategy with respect to productivity or growth patterns. A vigor index (VI) was also calculated from seedling data. VI was calculated from the final shoot length and germination rate data following the formula mentioned by Dezfuli et al. (2008) as VI $=\mathrm{SL}^{*} \mathrm{GR}$ where SL denotes shoot length at ten days and GR indicates germination rate. Agronomists usually use VI to separate seed lots before planting according to their vigor level.

\section{Seed Permeability test}

We tested the water permeability of seed from both parental lines across six time intervals $(0 \mathrm{hr}, 1 \mathrm{hr}, 3 \mathrm{hrs}$, $6 \mathrm{hrs}, 12 \mathrm{hrs}$ and $24 \mathrm{hrs}$ ) following the protocol described in Jaganathan et al. (2019). We replicated this test three times for both ecotypes. In brief, 50 seeds per replicate were weighed in an analytical balance and later placed on a moist Whatman No.1 filter paper in a 100-mm petri-dishes. These plates were kept in room temperature and the seed lot was reweighed at target time intervals.

\section{Data processing, statistics and QTL mapping}

We fit linear models for the measured phenotypic traits treating RIL genotype as a fixed effect. We also included temporal block in the model as a fixed effect covariate when the block had a significant effect on phenotypic traits. Most of our collected phenotypes except seed mass and shoot length at ten days had a significant block effect. We used PROC CORR from SAS to calculate genetic correlation between collected traits using RIL means as estimates of breeding values. Broad-sense heritability was estimated using h2boot software fitting one-way ANOVA among inbred lines with 1000 bootstrap runs (Phillips and Arnold 1999). Parental trait divergence was estimated by mean differences and significance tested with a $t$-test in SAS. Resulting p-values were adjusted for multiple testing via the Benjamin and Hochberg's (1995) method of False Discovery Rate (FDR) estimation.

All measured morphological traits in the RIL population were normally distributed except for Root Length (RL10), Shoot Length at ten days (SL10), Shoot Root Ratio (SRR) and shoot relative growth rate (RGR). These traits were log transformed before QTL mapping. We observed that parental hallii and filipes means flanked the peak of the distribution of the phenotypic trait values for most traits. However, we saw transgressive segregation for germination rate (GR), Relative Growth Rate (RGR), shoot length at five days (SL5) and root length (RL10) trait values (Supplementary Fig. 1).

We performed QTL mapping of seed and earlier growth related morphological traits on RIL breeding values by stepwise fitting of multiple QTL models in R/qtl package (Broman et al. 2003). The input file for QTL mapping including the linkage map and phenotypic traits are at supplementary file 1 . We used two functions to determine QTL positions and the estimation of additive effects and pairwise epistasis. We first calculated penalties for main effects and their interactions using Haley-Knott regression by 1000 permutations of the scan-two function for each phenotypic trait. We then performed a forward/backward stepwise search for 
models with a maximum of six QTL that optimized the penalized LOD score criterion using the stepwise procedure. Significance thresholds were determined at an experiment-wide Type 1 error rate of $\alpha=0.05$. Confidence intervals for each significant QTLs were calculated as the 1.5 LOD drop interval by using the qtlStats function from qtlTools (github.com/jtlovell/qtlTools).

\section{Tissues for RNAseq data and expression analyses}

We germinated hallii (HAL2 genotype) and filipes(FIL2 genotype) lines in a 3.5-inch pot in a Promix based soil mix prepared at the greenhouse located at UT Austin during Spring, 2019. Soils for the pot was prepared by mixing potting soil (Pro Mix BX Mycorise PRO), coarse manufactured clay products (Turface MVP), and fritted clay (Turface Profile) at a ratio of 6:1:1. Once germinated, we kept only one plant per pot and watered them every three days. Temperature and light condition were held at $28^{\circ} \mathrm{C}$ with a $12 \mathrm{hr}$ light $/ 12 \mathrm{hr}$ dark photoperiod throughout the growth period. We collected $50 \mathrm{mg}$ of seeds from six panicles for both halliiand filipes between $10 \mathrm{am}-12: 30 \mathrm{pm}$ on the $68^{\text {th }}$ day after planting from three representative maternal plants of bothhallii and filipes. We extracted RNA using PureLink Plant RNA reagent (Thermo Fisher Scientific) following the manufacturers protocol. RNA quality was evaluated by running an agarose gel for confirming the presence of ribosomal RNA bands. RNA was treated with Dnase I (Promega, USA) at a concentration of 1 unit/ $\mu \mathrm{g}$ of total RNA. RNAseq libraries were prepared following a modified protocol developed in Meyer et al. (2011). Six libraries were sequenced using the Illumina Hiseq-2500 at 1x150bp. Detail about sequence processing including filtering criteria, mapping, count generation and gene expression analyses strategies are discussed in the supplementary file 2. Raw sequencing files have been deposited on NCBI SRA as bioproject PRJNA666892, and six file names on this submission used in this study are mentioned in supplementary file 3. Gene expression counts are presented in supplementary file 4.

\section{Search for Candidate genes}

Our candidate gene discovery method consisted of a three-step procedure. First, we compiled all genes from QTL intervals based on the physical position of markers flanking the 1.5 LOD drop confidence interval using the genome references for Panicum hallii (Lovell et al. 2018b) https://phytozome.jgi.doe.gov/pz/portal.html\#!info?alias=Org_Phallii_er). Next, we narrowed this list by identifying only those genes showing differential expression in seeds between parental lines. Finally, we selected likely candidates based on their functional characteristics using their homologs in Arabidopsis thaliana as a reference.

\section{Results}

\section{Seed mass plasticity and trait variability in parental lines}

Parental lines exhibited considerable phenotypic divergence in seed size, dormancy, and earlier growth traits between lowland and upland ecotypes (Fig.1). We tested for genotype (G), sites (E) and GxE interaction effects on parental data collected from reciprocal sites. Seed mass showed significant differences for genotype main effects $(\mathrm{P}<0.001)$ but did not show significant effects of reciprocal sites $(\mathrm{P}=0.84)$ or for $\mathrm{GxE}$ interaction $(\mathrm{P}=0.28)$. We also conducted a germination experiment in the lab with seeds collected from our reciprocal sites to evaluate if plants growing in reciprocal habitats show different dormancy. However, no significant differences were observed on dormancy trait between reciprocal sites $(\mathrm{P}=0.37)$ and for $\mathrm{GxE}$ interaction $(\mathrm{P}=0.72)$. However, we found highly significant differences for genotype main effects $(\mathrm{P}<0.001)$ (Fig.1, Supplementary File 5). Additionally, we tested germination rate for the non-germinated seeds by removing seed coats for both ecotypes. Our data showed that scarification technique effectively increased seed germination for the dormant hallii seeds. We found halliiseeds germination was increased to $88.2 \%$ after removing seed coats which was $57 \%$ higher than their regular germination rate (Supplementary File 5). This result confirms that the seed dormancy in the upland ecotype is not due to seed viability issue, upland seeds are viable but they remain dormant.

In growth chamber experiments, we found that parental lines significantly differed for all 13 measured traits. All collected traits and their types are defined in supplementary file 6. The upland ecotype (hallii) had 
higher values in all traits compared to the lowland (filipes ) ecotype except for the germination rate, shoot to root ratio, and seedling vigor (Fig.2, Table 1). The upland halliiecotype had $56 \%$ greater seed mass than the filipes ecotype and the germination rate in filipes is $63 \%$ greater thanhallii (Supplementary File 7, Table 1). The mean difference in germination timing between hallii and filipes is $60 \mathrm{hrs}( \pm 2.7)$, with filipes germinating earlier than hallii . Thehallii ecotype has seeds with greater length (16\%), width (26\%), area $(35 \%)$ and roundness $(12 \%)$ compared to filipes . Initial seedling height after 5 days is greater $(10 \%)$ in hallii . This growth difference increased over time with 10-day measures that were $24 \%$ and $73 \%$ greater for seedling height and root length inhallii (Table 1, Supplementary File 8). The filipes shoot growth is greater than their root growth, while the reverse is observed in hallii (Fig.1, Table 1). Shoot relative growth rate was calculated from the mean of plant height data, which also showed higher trait values for hallii than filipes .

\section{Heritability, Phenotypic patterns and pairwise relationship among RILs}

Generally, RIL means for all traits were at intermediate values relative to parental lines except for germination time, relative growth rate and shoot root ratio traits (Fig. 2). We estimated broad-sense heritability $\left(\mathrm{H}^{2}\right)$ among RILs in the population as the proportion of total phenotypic variation due to genetic variation among RIL lines. All measured traits were heritable with heritability ranging from 18 to $97 \%$ (bootstrapbased significance, $P<0.001)$. The least heritable traits were seed area (0.18), germination rate $(0.24)$, relative growth rate (0.25), vigor index (0.26) and shoot length at 5 days from germination time (0.30) data. Seed mass had the highest heritability (0.97) among all studied traits. The heritability of germination time and root length was also high, 0.76 and 0.63 for these two traits respectively (Table1).

We observed significant genetic correlation between phenotypic traits in the RIL population. Pairwise correlation of individual RIL means showed that 55 out of 78 pairwise comparisons in the RIL population were significantly correlated (FDR-corrected $P$-values [?]0.05) (Supplementary File 9). Seed mass was positively correlated to seed length $(\mathrm{r}=0.49, \mathrm{P}<0.001)$, seed width $(\mathrm{r}=0.84, \mathrm{P}<0.001)$, seed area $(\mathrm{r}=0.65$, $\mathrm{P}<0.001)$, shoot length at 10 days $(\mathrm{r}=0.23, \mathrm{P}=0.0002)$ and root length $(\mathrm{r}=0.31, \mathrm{P}<0.001)$, but negatively correlated with germination rate $(\mathrm{r}=-0.43, \mathrm{P}<0.001)$ and vigor index $(\mathrm{r}=-0.31, \mathrm{P}<0.001)$. Germination rate is negatively correlated with all seed shape related data but positively correlated with shoot length at five $(\mathrm{r}=0.34, \mathrm{P}<0.001)$ and ten $(\mathrm{r}=0.14, \mathrm{P}=0.03)$ days after germination (Fig. 2). Shoot length at ten days had a positive correlation with shoot relative growth rate data $(\mathrm{r}=0.58, \mathrm{P}<$ 0.001), explaining that observation that relative growth is strongly driven by shoot length data collected at ten days. (Supplementary File 9).

\section{Genetic architecture underlying seed size, germination and seedling growth traits}

We identified 45 quantitative trait loci (QTL) from 12 morphological traits using stepwise QTL models (Table 2, Supplementary Fig. 2). Seed size and seed shape related traits comprised over half (53\%, 24 QTL) of the identified QTL. The majority of the QTL (38 out of 45 QTL) had overlapping 1.5 LODdrop confidence intervals with a QTL for at least one other trait (Table 2), suggesting that in many cases phenotypic correlations are reflective of underlying genetic correlations resulting from physical linkage or pleiotropy. We also observed that $87 \%$ of the identified QTL affected phenotypic variation in the expected direction based on observed evolutionary divergences between hallii andfilipes ecotypes of $P$. hallii . For example, thehallii allele increased trait values relative to filipesalleles for seed mass, seed length, seed width, seed area, shoot length and root length data. On the other hand, the filipes allele increased germination rate and vigor index traits. For a few traits, we observed mixed QTL effects in that the direction of effects were more complex than expected by ecotype divergence. For example, for SL5 we found two out of the five QTL effects were increased by thefilipes allele (Table 2).

Only $15 \%$ of identified QTL (7 out of 45) had unique position in the linkage map. Shoot length at 5 days had two unique QTL, one occurring at1@25.7 and the other at 4@47.1. Vigor index had two unique QTL and both of them are positioned on chr8 (8@13.6 and 8@49.2). Germination rate had one unique QTL 2@26.3, germination time has one 6@50 and seed roundness has one at 5@13.3 (Table 2, Fig. 3). In addition, we identified multiple QTL for most of the measured traits except for the shoot length at 10 days, root length 
and shoot-root ratio traits. Shoot length at 5 days and 10 days QTL overlaps at 2@126, on the other hand, QTL for root length and shoot root ratio overlaps at 3@11.7. Despite these traits having high heritability (ranging from 0.39 to 0.63 ; Table 1), we detected only single QTL with low percent of variance explained (PVE) for these traits (PVE $<10 \%)$, suggesting there may be many undetected loci controlling these traits or that our heritability estimates are inflated by maternal environmental or epigenetic effects.

\section{QTL colocalization, allelic effects, genetic trade-offs and epistasis}

Overall, we mapped 13 chromosomal regions with overlapping QTL and consider these QTL clusters or hotspots. Here, we identify QTL clusters (CL) by chromosome and numerical order from the telomere of each chromosome. We found QTL clusters driving associations of between two and four traits (Table 2, Fig.3). We found some expected colocalization in the QTL clusters between traits. For example, seed shape features (e.g., seed length, seed width etc.) QTL were colocalized with seed mass traits. Similarly, composite traits (e.g., vigor index, shoot root ratio etc.) also showed colocalization with traits used to calculate that composite trait (e.g., germination rate, root length etc.). For example, two of the identified vigor index QTL clustered with germination rate (Table 2, Fig. 3).

In addition to these expected colocalization, we also identified interesting and potentially functionally related combinations of QTL colocalizations between seed mass, earlier growth and germination traits. For example, seed mass, seed shape and five days old seedling height QTL colocalized to a cluster on the end of chromosome 1 (CL1.3 at 1@108.2). In that region, seed mass and five days old seedling height had antagonistic additive effects with the hallii allele increasing trait values for seed mass and decreased trait values for five days old seedling height. Four traits including germination time and germination rate QTL occurred in a cluster on chromosome 9 (CL9.1 at 9@128.1) also having antagonistic additive effects in the same direction as parental divergence. Here, the filipes allele increased trait values for germination rate but decreased for germination time. In another case, four traits showed QTL clustering on Chr2 (CL2.1 at 2@85.3), seed size and germination rate clustered with antagonistic additive effects. We also found these two traits colocalized on Chr5 (CL5.1 a5 5@130) QTL cluster. As expected, in both cases halliiallele increased seed mass and decreased germination rate trait values (Table 2).

Finally, we also detected one pairwise epistatic interaction for germination time occurring between QTL on Chr6 (6@50) and Chr9 (9@121.3) (Fig. 4, Table 2). Here, individuals that are homozygous for the

hallii allele at both loci have delayed germination, but this pattern is masked in any of the alternative hybrid combinations.

\section{Candidate genes from QTL and their expression variation between parental lines}

We first identified differential expressed genes between halliiand filipes in seeds by fitting a linear model at False Discovery Rate of 0.05 after normalizing the raw counts with the kdmm normalization technique. We detected 9318 differentially expressed (DE) genes between two parental lines (Fig.4). We observed that many of DE genes (9038) had higher expression in filipes, with the reverse in only a very small number of genes (280 genes (Supplementary File 4)). These DE genes were significantly enriched to pathways including protein transport, cellular localization, and RNA processing. We used this list of DE genes to look for likely candidate genes from several QTL intervals. We focused on QTL regions with interesting overlapping QTL sets.

One very interesting candidate is GID1C (Pahal.C03051), a gibberellin (GA) receptor. This gene is located at QTL cluster CL3.2 at 3@86.3 (Table 2) related to seed size. In A. thaliana, this gene (AT5G27320) is a key positive regulator promoting seed germination by degrading DELLA protein, which acts as the repressor for GA response during seed germination (Ge and Steber 2018). The expression of this gene was significantly higher in filipes seed compared tohallii seed transcripts (Supplementary File 10). Another candidate gene (CYP707A1, Pahal.A03071) was located at CL7.1 (7@71.3, Table 2). This gene has been reported to be predominantly expressed during seed maturation. It reduces ABA levels during seed development in $A$. thaliana and is downregulated in seeds, resulting in increased levels of ABA at that stage to maintain 
dormancy (Okamoto et al. 2006). In our study, we found that this gene has been downregulated in the hallii genotype compared to filipes(Supplementary File 10), which might increase the ABA level inhallii seed and promote dormancy.

We detected a strong candidate gene (TT7, Pahal.D02180)from the QTL cluster at CL9.1 (Chr9@128.1 (Table 2)). In A. thaliana, mutant of $T T 7$ showed higher germination efficiency when compared to wild type. This mutant reduced seed dormancy by enhancing seed coat permeability in Arabidopsis (Debeaujon and Koornneef 2000; Debeaujon et al. 2000). This gene is upregulated inhallii seed (log2 fold-change difference 1.8), which may reduce seed coat permeability in hallii compared to the filipesecotype. BAN (Pahal.G02426) is an interesting candidate gene for QTL CL7.1 (Chr7@71.3). This gene was found upregulated in halliiseed as well (log2 fold-change difference 1.99), and plays a central role in proanthocyanidins (PA) accumulation in seeds (Debeaujon et al. 2003). BAN has an indirect effect maintaining dormancy by promoting ABA biogenesis in seeds. Interestingly, PAs are biosynthesized and accumulated in the seed coat. Thus, physically removing seed coat would lower the amount of PA and ABA level to promote seed germination (Marles et al. 2003; Jia et al. 2012). We also discovered some core ABA responsive genes in QTL clusters that are associated to seed dormancy and growth, including RCAR3 (PLY8), CIPK3, SnRK2.10, HAI2 and HAI3 genes. Candidate genes information and with their fold change differences in gene expression can be found in Supplementary File 10.

\section{Testing candidate gene function and non-synonymous changes in coding sequences}

We could not confirm the function of the candidate genes discovered in this study with genetic manipulations because transformation is still challenging in non-model systems like P. hallii . However, we evaluated some obvious functions of two candidate genes by additional phenotyping experiments. First, we detected upregulation of the candidate gene TT7 in hallii; TT7 has been shown to play a role in seed coat permeability in A. thaliana. The function of the gene is interesting because one of the major reasons for physical dormancy in seeds is impermeability of the seed coat to water (Baskin et al. 2000; Baskin 2003a; Leadem 1997). In this case, divergence in TT7 expression or its protein might be involved in reducing hallii seed coat permeability to water causing increased physical dormancy. To test this hypothesis, we measured seed permeability between hallii and filipes seeds at six-time intervals (0hr, 1hr, 3hrs, 6hrs, 12hrs and 24hrs). Our data showed that the upland hallii is less permeable to water compared tofilipes ecotype. The first two measured time points $(0 \mathrm{hr}$ and $1 \mathrm{hr})$ did not show a significant difference in water imbibition between the two parental lines, but from $3 \mathrm{hrs}$ and thereafter hallii andfilipes water imbibition rate significantly differed withfilipes imbibed more water when compared to hallii(Fig.5). Second, we detected upregulation of the $B A N$ gene inhallii seed; $B A N$ is located in the seed coat in $A$. thaliana, where it increases dormancy by promoting $\mathrm{ABA}$ expression in the seed. In $A$. thaliana, $B A N$ is the master regulator of proanthocyanidins accumulation in seeds which increases ABA level (Jia et al. 2012). Thus, we hypothesized that seed coat is also causing increased dormancy in this species. We measured germination rate for both hallii and filipes after removing their seed coats and found a $57 \%$ germination rate increase in hallii from seeds without seed coat (Fig.5). The increased expression of these two genes may explain the increased dormancy in hallii, however, further studies are required to prove a causal role of $T T 7$ and BANgenes in P.halli .

In addition to our experimental manipulations, we looked at coding sequence (CDS) polymorphisms between hallii and filipesfor four candidate genes discussed here. We found no non-synonymous changes in protein sequences for GID1C and CYP707A1. However, we found non-synonymous changes in protein sequences for both TT7 and BAN genes. There were 5 amino acid (AA) substitutions for TT7 genes and 26 AA substitutions for BAN genes between hallii and filipes (Supplementary File 11).

\section{Discussion}

Populations adapting to heterogeneous environments will develop genetic differences over time in response to selection. These may ultimately lead to ecotype formation with distinct morphological and/or physiological characteristics that provide an environment-specific fitness advantage. However, we know surprisingly little about the genetic basis of parallel evolution among ecotype-differentiating traits. In addition to that, studies 
looked at genetic basis of ecotypic differentiation are often based on seedling transplantation (Lowry and Willis 2010b; Fournier-Level et al. 2013) and so may exclude important aspects of divergence in earlier life stages (Donohue et al. 2010; Donohue 2014). This is surprising as early life stage are often crucial because this vulnerable period of development can suffer from high mortality rates (Donohue et al. 2010; Kitajima and Fenner 2000), thus selection may be severe during this part of the life cycle. Additionally, early life experiences often have non-linear effects on later life history traits (Beckerman et al. 2002). It may be difficult or impossible to fully understand adaptation if we ignore juvenal stages.

In this study, we examined ecotypic divergence and genetic basis of differences between xeric and mesic ecotypes at the seed and seedling stages in $P$. hallii to evaluate early life stages that may contribute to local adaptation. Reciprocal plantings of ecotypes revealed that seed mass and germination rate were quite stable, and that local conditions have little impact on seed mass or germination rates (Fig.1, Supplementary File 5). We mapped QTL for twelve traits with several large effect QTL colocalizing to a relatively small number of genomic regions. Overall, the direction of QTL effects is predominantly in the direction of putative adaptive divergence. This pattern is consistent with a hypothesis of strong directional selection on seed related traits (Rieseberg et al. 2002; Orr 1998). We also identified clear genetic trade-offs between seed mass and germination rate at two QTL and identified a number of candidate genes based on QTL localization, patterns of gene expression, and functional annotation. These data suggest that seed size, dormancy and seedling vigor traits may have jointly evolved in the process of ecotype divergence. Overall, this study helps broaden our understanding on ecotype differentiating traits from seed biology and early life stages perspective.

\section{Parental divergence and trait plasticity}

Plant populations are generally limited by either the abundance and quality of seed for seedling recruitment or by the availability of microsites for seedling establishment. One hypothesis is that aspects of habitat quality and the local competitive environments may therefore play key selective roles in the evolution of seed and seedling phenotypes. In light of this theory, it is interesting to speculate on the patterns of ecotypic divergence in P. hallii . P.hallii var. hallii is widespread ecotype and occurs primarily in xeric habitats in rocky, dry, and calcareous soils (Smeins et al. 1976; Waller 1976; Hatch et al. 1999) and with relatively low ground cover or competition. In contrast var. filipes is located primarily in mesic and seasonal wet areas (Gould 1975; Waller 1976) in dense coastal prairie habitats. Our data show that hallii produces larger seeds with delayed germination and strong dormancy compared to filipes. In addition, hallii roots grows $73 \%$ longer than var. filipes roots after ten days of seedling growth (Fig.1, Table 1). Typically, increased root growth from large seeds would result in an establishment benefit in resource poor sites. Thus, having larger seed mass, high dormancy, delayed germination time and faster root growth may be selected for hallii to survive hazards of establishment in harsh southwestern habitats. Our results support the model developed for maintenance of seed size diversity by Muller-Landau (2010), where species coexist in heterogenous habitats by a tolerance-fecundity trade-off. Under this mechanism, species with larger seeds win a stressful environment (e.g., too dry, too shady etc.) due to their higher tolerance to stress while small seeded species win in competitive habitats due to their higher fecundity. We found filipes commonly in competitive coastal prairie environments with a high density of other grasses (e.g., Bouteloua rigidiseta, Nassella leucotricha, Hilaria belangeri, Bouteloua dactyloides etc.). Our data showed thatfilipes has small seeds with fast germination time and low dormancy when compared to hallii (Table 1, Fig.2). We hypothesize that filipes establishment is primarily microsite limited. Here, selection may have favored the production of a large number of small seeds with attributes allowing establishment in rare disturbed patches of habitat.

\section{The Genetics of Ecotypic Divergence}

Plant ecotypic divergence caused by adaptations to xeric and mesic habitats provides ample evidence of ecological functions that contribute to the process of speciation (Clausen 1951; Kruckeberg 1986; Rajakaruna 2004; Lowry 2012; Lowry et al. 2015). Understanding the underlying genetic basis of ecotypic divergence helps to better understand the degree to which adaptive evolution was constrained or facilitated by the structure of genetic variation. In this study, we found colocalization of QTL occurs for the common set of traits involved in xeric and mesic ecotypic divergence, suggesting that these traits evolve non-independently. 
We observed that seed mass QTL colocalized with all other measured traits (except germination time) at different regions of the chromosome, suggesting that in many cases seed mass, seed shape and earlier growthrelated traits may exhibit pleiotropy, or be controlled either by different genes tightly linked to each other or by the same genes controlling multiple traits.

We also found evidence for genetic trade-off between seed-based life history traits at chromosomal regions. Most of the discovered QTL clusters in this study had antagonistic effects across traits. The finding of antagonistic additive effects for QTL cluster implies that seed based related traits are under strong selection between $P$. hallii lowland and upland ecotypes. For example, seed mass and germination rate colocalized at two chromosomal regions where thehallii allele increased seed mass but decreased germination rate. However, a negative relationship between seed mass and germination is not consistent across all species. Several studies reported no genetic correlation between these two traits in multiple species including Medicago truncatula and Brassica oleracea (Dias et al. 2011; Bettey et al. 2000). Dechaine et al. (2014) showed a positive genetic correlation between seed mass and germination trait inBrassica rapa. In tomato, no genetic correlation was found between seed size and germination rate when tested in greenhouse condition (Khan et al. 2012) but a negative genetic correlation was observed when tested under different nutritional conditions (Geshnizjani et al. 2020). Our result suggests that $P$. hallii ecotypes may be under strong selection pressures to evolve either large seed/dormancy or small seed/no dormancy trait combinations. The observed genetic covariation in the RIL population suggests that the major axis of standing genetic variation would support the rapid evolution of these trait combinations, while potentially constraining evolution of the opposite combination of traits. (Fig.6). In addition, large seeds with vigorous root growth might be favored in dryer and resource limited habitats (Fig. 6). Thus, our mapping data support the idea that large seeds/ dormancy and longer root growth trait combination may have been an important adaptation for hallii as it diverged from a coastal ancestor and invaded dry, calcareous habitats across the southwest.

We have consistently found that upland and lowland ecotype differentiating traits colocalized in P. hallii to a relatively small number of chromosomal regions. Lowry et al. (2015) mapped five QTL to a locus on chromosome 5 with traits that are involved in ecotypic divergence using an $\mathrm{F}_{2}$ population. In our study, three traits (seed mass, germination rate and seed width) colocalized to this region. Interestingly, all five traits that Lowry et al. (2015) mapped had additive effects in the same direction where thefilipes allele increased the trait values. Khasanova et al. (2019) also mapped five traits to the same region. In that study, all traits also had additive effects in the same direction with thefilipes allele increasing trait values. In our study this QTL had contrasting effects on seed size and germination, in that thehallii allele increased seed related trait values and decreased germination rate. Our study therefore provides further support for a major pleiotropic region that contributes to ecotype differentiation in $P$. hallii .

\section{Candidate genes and their expression differences}

Seed size, germination and early plant growth are complex physiological process. These traits are regulated by a combination of environmental, physiological and morphological signals with both shared and competing effects (Li et al. 2019; Graeber et al. 2012; Finkelstein et al. 2008; Finch-Savage and Leubner-Metzger 2006). Understanding genes and their mechanisms involved in these processes are crucial to understand plants performance, fitness and adaptation. We further explored several QTL clusters to identify candidate genes that might underlie the observed ecotypic divergence. For example, we found several genes that break dormancy in A. thaliana are consistently upregulated in the non-dormant filipes ecotype. GID1C and $C Y P^{707 A 1}$ are two such examples, where GID1C promotes germination by degrading negative regulators (DELLA ) of GA signaling during seed germination (Ge and Steber 2018) and CYP707A1 promotes seed germination by reducing ABA level in seeds (Okamoto et al. 2006).

On the other hand, we detected two interesting candidates with higher gene expressions in hallii seeds that have been reported to increase seed dormancy. This is an important trait for species adapting at heterogenous habitats differing by soil water content. Seed dormancy may ensure a species ability to survive natural catastrophes, decrease intraspecific competition or halt germination for the most appropriate season (Finkelstein et al. 2008). In $P$. hallii this trait is probably under strong selection along with seed size 
variations, and we constantly discovered higher seed dormancy for the upland ecotype adapted in rocky, calcareous soil. Interestingly, several of our candidate genes are involved in diverse types of dormancy, including physical dormancy and physiological dormancy in seeds. These dormancy types are common in wild species and considered the main drivers for seed dormancy across plant species (Baskin and Baskin 1998; Baskin et al. 2000; Baskin 2003b; Baskin and Baskin 2004). One candidate, TT7 maintains seed dormancy by reducing the permeability of the seed coat to water and chemical compounds (Jaganathan et al. 2019). The other gene, $B A N$, increases seed dormancy by promoting seed ABA levels by an indirect mechanism involving proanthocyanidin accumulation in seeds which increases the ABA level (Jia et al. 2012). Future studies will be needed to test whether natural alleles at these candidates underly dormancy QTL in P. hallii

\section{Conclusions}

Seed mass plays an important role in plant ecology, as it connects plant reproductive strategies with dormancy, seedling establishment and vegetative growth (Leishman et al. 2000; Grime et al. 2014; Leishman and Westoby 1992). In this study, we explored several facets of ecotype differentiating traits from a seed biology perspective. Our study reinforces a pattern that have been observed in multiple species, wherein genetic studies find that ecotype differentiating traits colocalize to common genomic regions (Latta and Gardner 2009; Lovell et al. 2013; Lowry et al. 2015; Khasanova et al. 2019; Hall et al. 2006; Lowry and Willis 2010b). In our study, only a handful of identified QTL had unique positions that did not colocalize with another QTL. We used gene expression data to identify potential candidate genes that could contribute to $P$. hallii ecotypic divergence related seed biology. Once fine mapping or transformation becomes feasible in this species, further work can identify candidate genes to gain better insight into the molecular details underlying local adaptation and ecotypic divergence in $P$. hallii. Overall, our data support the functional integration of seed size and seed dormancy traits, an exciting next step will be to evaluate the fitness and population impact of the seed variation in different habitats.

\section{Author contribution}

SR and TEJ designed the experiment. SR conducted the experiment, analyzed the data and wrote the manuscript. TEJ provided feedback on analyses and edited the manuscript.

\section{Acknowledgement}

Thanks to Brandon Campitelli, Allison Hutt \& Shayan Noshir Bhathena for helping during seed collection. Taslima Haque helped with the initial set up of the experiment. Juan Diego Palacio Mejia provided helpful suggestions during the design of the experimental setup. Robert Heckman gave important comments and valuable insights during the work, analyses and manuscript writing. Alice MacQueen contributed important comments while writing the manuscript. Xiaoyu Weng, Bhaskara Badiger and Joseph Edward gave helpful suggestions during manuscript writing and analyses. Thanks to Jake Herring, Director of Land Conservation, from Coastal Bend Bays and Estuaries Program for allowing us to conduct field plantings at the Nueces Delta Preserve, Odem Texas. Rob Plowes provided space at the Brackenridge Field Lab site at UT Austin. Shane Merrell provided technical support while setting up the experiment in the greenhouse facility. This research was supported by an NSF Plant Genome Research Program Grant (IOS-0922457) to TEJ. Authors also acknowledge Texas Ecolab support to SR for conducting field work.

\section{References}

Abramoff MD, Magalhaes PJ, Ram SJ (2004) Image processing with ImageJ. Biophotonics international 11 (7):36-42

Agrawal AA, Conner JK, Rasmann S (2010) Tradeoffs and negative correlations in evolutionary ecology. Evolution since Darwin: the first 150:243-268

Agren J, Oakley CG, McKay JK, Lovell JT, Schemske DW (2013) Genetic mapping of adaptation reveals fitness tradeoffs in Arabidopsis thaliana. Proceedings of the National Academy of Sciences 110 (52):21077- 
Alonso-Blanco C, Bentsink L, Hanhart CJ, Blankestijn-de Vries H, Koornneef M (2003) Analysis of natural allelic variation at seed dormancy loci of Arabidopsis thaliana. Genetics 164 (2):711-729

Anderson JT, LEE CR, Rushworth CA, Colautti RI, MITCHELL-OLDS T (2013) Genetic trade-offs and conditional neutrality contribute to local adaptation. Molecular Ecology 22 (3):699-708

Baker HG (1972) Seed weight in relation to environmental conditions in California. Ecology 53 (6):997-1010

Baskin CC (2003a) Breaking physical dormancy in seeds-focussing on the lens. New Phytologist 158 (2):229232

Baskin CC (2003b) Breaking physical dormancy in seeds: focussing on the lens. The New Phytologist 158 (2):229-232

Baskin CC, Baskin JM (1998) Seeds: ecology, biogeography, and, evolution of dormancy and germination. Elsevier,

Baskin JM, Baskin CC (2004) A classification system for seed dormancy. Seed science research 14 (1):1-16

Baskin JM, Baskin CC, Li X (2000) Taxonomy, anatomy and evolution of physical dormancy in seeds. Plant species biology 15 (2):139-152

Beckerman A, Benton TG, Ranta E, Kaitala V, Lundberg P (2002) Population dynamic consequences of delayed life-history effects. Trends in Ecology \& Evolution 17 (6):263-269

Benjamini Y, Hochberg Y (1995) Controlling the false discovery rate: a practical and powerful approach to multiple testing. Journal of the Royal statistical society: series B (Methodological) 57 (1):289-300

Bentsink L, Hanson J, Hanhart CJ, Blankestijn-de Vries H, Coltrane C, Keizer P, El-Lithy M, Alonso-Blanco C, de Andres MT, Reymond M (2010) Natural variation for seed dormancy in Arabidopsis is regulated by additive genetic and molecular pathways. Proceedings of the National Academy of Sciences 107 (9):4264-4269

Bentsink L, Jowett J, Hanhart CJ, Koornneef M (2006) Cloning of DOG1, a quantitative trait locus controlling seed dormancy in Arabidopsis. Proceedings of the National Academy of Sciences 103 (45):17042-17047

Bentsink L, Soppe W, Koornneef M (2007) of Book: Seed Development, Dormancy and Germination. In. Blackwell Publishing,

Bettey M, Finch-Savage W, King GJ, Lynn J (2000) Quantitative genetic analysis of seed vigour and preemergence seedling growth traits in Brassica oleracea. New Phytologist 148 (2):277-286

Bradford K, Nonogaki H (2008) Annual plant reviews, seed development, dormancy and germination, vol 27. John Wiley \& Sons,

Broman KW, Wu H, Sen Ś, Churchill GA (2003) R/qtl: QTL mapping in experimental crosses. Bioinformatics 19 (7):889-890

Childs DZ, Metcalf CJE, Rees M (2010) Evolutionary bet-hedging in the real world: empirical evidence and challenges revealed by plants. Proceedings of the Royal Society B: Biological Sciences 277 (1697):3055-3064

Clausen J (1951) Stages in the evolution of plant species. Stages in the evolution of plant species (6d)

Conover DO, Duffy TA, Hice LA (2009) The covariance between genetic and environmental influences across ecological gradients. Annals of the New York Academy of Sciences 1168 (1):100-129

Davis MB, Shaw RG (2001) Range shifts and adaptive responses to Quaternary climate change. Science 292 (5517):673-679 
Daws MI, Ballard C, Mullins CE, Garwood NC, Murray B, Pearson TR, Burslem DF (2007) Allometric relationships between seed mass and seedling characteristics reveal trade-offs for neotropical gap-dependent species. Oecologia 154 (3):445-454

De Jong G (2005) Evolution of phenotypic plasticity: patterns of plasticity and the emergence of ecotypes. New Phytologist 166 (1):101-118

Debeaujon I, Koornneef M (2000) Gibberellin requirement for Arabidopsis seed germination is determined both by testa characteristics and embryonic abscisic acid. Plant physiology 122 (2):415-424

Debeaujon I, Léon-Kloosterziel KM, Koornneef M (2000) Influence of the testa on seed dormancy, germination, and longevity in Arabidopsis. Plant physiology 122 (2):403-414

Debeaujon I, Nesi N, Perez P, Devic M, Grandjean O, Caboche M, Lepiniec L (2003) Proanthocyanidinaccumulating cells in Arabidopsis testa: regulation of differentiation and role in seed development. The Plant Cell 15 (11):2514-2531

Dechaine JM, Brock MT, Weinig C (2014) QTL architecture of reproductive fitness characters in Brassica rapa. BMC plant biology $14(1): 66$

Dezfuli PM, Sharif-Zadeh F, Janmohammadi M (2008) Influence of priming techniques on seed germination behavior of maize inbred lines (Zea mays L.). ARPN Journal of Agricultural and Biological Science 3 (3):22-25

Dias PMB, Brunel-Muguet S, Dürr C, Huguet T, Demilly D, Wagner M-H, Teulat-Merah B (2011) QTL analysis of seed germination and pre-emergence growth at extreme temperatures in Medicago truncatula. Theoretical and Applied Genetics 122 (2):429-444

Donohue K (2014) Why ontogeny matters during adaptation: Developmental niche construction and pleiotorpy across the life cycle in Arabidopsis thaliana. Evolution 68 (1):32-47

Donohue K, Rubio de Casas R, Burghardt L, Kovach K, Willis CG (2010) Germination, postgermination adaptation, and species ecological ranges. Annual review of ecology, evolution, and systematics 41:293-319

Falconer D, Mackay T (1996) Introduction to quantitative genetics. Essex. UK: Longman Group

Finch-Savage WE, Leubner-Metzger G (2006) Seed dormancy and the control of germination. New phytologist $171(3): 501-523$

Finkelstein R, Reeves W, Ariizumi T, Steber C (2008) Molecular aspects of seed dormancy. Annual review of plant biology 59

Fournier-Level A, Wilczek AM, Cooper MD, Roe JL, Anderson J, Eaton D, Moyers BT, Petipas RH, Schaeffer RN, Pieper B (2013) Paths to selection on life history loci in different natural environments across the native range of A rabidopsis thaliana. Molecular ecology 22 (13):3552-3566

Futuyma DJ, Moreno G (1988) The evolution of ecological specialization. Annual review of ecology and systematics 19 (1):207-233

Ge W, Steber CM (2018) Positive and negative regulation of seed germination by the Arabidopsis GA hormone receptors, GID 1a, b, and c. Plant direct 2 (9):e00083

Geshnizjani N, Snoek BL, Willems LA, Rienstra JA, Nijveen H, Hilhorst HW, Ligterink W (2020) Detection of QTLs for genotypex environment interactions in tomato seeds and seedlings. Plant, Cell \& Environment

Gould BA, Palacio-Mejia JD, Jenkins J, Mamidi S, Barry K, Schmutz J, Juenger TE, Lowry DB (2018) Population genomics and climate adaptation of a $\mathrm{C} 4$ perennial grass, Panicum hallii (Poaceae). BMC genomics $19(1): 792$

Gould F (1975) The grasses of Texas. Texas A. \& M. Univ Press, College Station, TX 653 
Graeber K, Nakabayashi K, Miatton E, Leubner-Metzger G, Soppe WJ (2012) Molecular mechanisms of seed dormancy. Plant, cell \& environment 35 (10):1769-1786

Grandillo S, Tanksley S (1996) QTL analysis of horticultural traits differentiating the cultivated tomato from the closely related species Lycopersicon pimpinellifolium. Theoretical and Applied Genetics 92 (8):935-951

Grime JP, Hodgson JG, Hunt R (2014) Comparative plant ecology: a functional approach to common British species. Springer,

Hall MC, Basten CJ, Willis JH (2006) Pleiotropic quantitative trait loci contribute to population divergence in traits associated with life-history variation in Mimulus guttatus. Genetics 172 (3):1829-1844

Harel D, Holzapfel C, Sternberg M (2011) Seed mass and dormancy of annual plant populations and communities decreases with aridity and rainfall predictability. Basic and Applied Ecology 12 (8):674-684

Hatch SL, Schuster JL, Drawe DL (1999) Grasses of the Texas Gulf prairies and marshes. vol 24. Texas A\&M University Press,

Huang X, Schmitt J, Dorn L, Griffith C, Effgen S, Takao S, Koornneef M, Donohue K (2010) The earliest stages of adaptation in an experimental plant population: strong selection on QTLS for seed dormancy. Molecular ecology 19 (7):1335-1351

Jaganathan GK, Li J, Biddick M, Han K, Song D, Yang Y, Han Y, Liu B (2019) Mechanisms underpinning the onset of seed coat impermeability and dormancy-break in Astragalus adsurgens. Scientific reports 9 $(1): 1-10$

Jasmin JN, Kassen R (2007) On the experimental evolution of specialization and diversity in heterogeneous environments. Ecology letters 10 (4):272-281

Jia L, Wu Q, Ye N, Liu R, Shi L, Xu W, Zhi H, Rahman ARB, Xia Y, Zhang J (2012) Proanthocyanidins inhibit seed germination by maintaining a high level of abscisic acid in Arabidopsis thaliana F. Journal of Integrative Plant Biology 54 (9):663-673

Juenger TE (2013) Natural variation and genetic constraints on drought tolerance. Current opinion in plant biology 16 (3):274-281

Jurado E, Westoby M (1992) Seedling growth in relation to seed size among species of arid Australia. Journal of Ecology:407-416

Kearsey MJ (1998) The principles of QTL analysis (a minimal mathematics approach). Journal of experimental botany 49 (327):1619-1623

Khan N, Kazmi RH, Willems LA, Van Heusden AW, Ligterink W, Hilhorst HW (2012) Exploring the natural variation for seedling traits and their link with seed dimensions in tomato. PLoS One 7 (8):e43991

Khasanova A, Lovell JT, Bonnette J, Weng X, Jenkins J, Yoshinaga Y, Schmutz J, Juenger T (2019) The genetic architecture of shoot and root trait divergence between mesic and xeric ecotypes of a perennial grass. Frontiers in plant science 10:366

Kimura E, Fransen SC, Collins HP, Guy SO, Johnston WJ (2015) Breaking seed dormancy of switchgrass (Panicum virgatum L.): a review. biomass and bioenergy 80:94-101

Kitajima K, Fenner M (2000) Ecology of seedling regeneration. Seeds: The ecology of regeneration in plant communities 2:331-359

Kruckeberg AR (1986) An essay: the stimulus of unusual geologies for plant speciation. Systematic Botany:455-463

Lacerda DR, Lemos Filho JP, Goulart MF, Ribeiro RA, Lovato MB (2004) Seed-dormancy variation in natural populations of two tropical leguminous tree species: Senna multijuga (Caesalpinoideae) and Plathymenia 
reticulata (Mimosoideae). Seed Science Research 14 (2):127

Latta RG, Gardner KM (2009) Natural selection on pleiotropic quantitative trait loci affecting a life-history trade-off in Avena barbata. Evolution: International Journal of Organic Evolution 63 (8):2153-2163

Leadem CL (1997) Dormancy-unlocking seed secrets. National Proceedings, Forest and Conservation Nursery Associations Gen Tech Rep PNW-G TR-419 Portland, OR: US Department of Agriculture, Forest Service, Pacific Northwest Research Station:43-52

Leishman MR, Westoby M (1992) Classifying plants into groups on the basis of associations of individual traits-evidence from Australian semi-arid woodlands. Journal of ecology:417-424

Leishman MR, Wright IJ, Moles AT, Westoby M (2000) The evolutionary ecology of seed size. Seeds: the ecology of regeneration in plant communities 2:31-57

Li N, Xu R, Li Y (2019) Molecular networks of seed size control in plants. Annual review of plant biology 70:435-463

Lloret F, Casanovas C, Penuelas J (1999) Seedling survival of Mediterranean shrubland species in relation to root: shoot ratio, seed size and water and nitrogen use. Functional Ecology 13 (2):210-216

Lovell JT, Jenkins J, Lowry DB, Mamidi S, Sreedasyam A, Weng X, Barry K, Bonnette J, Campitelli B, Daum C (2018a) The genomic landscape of molecular responses to natural drought stress in Panicum hallii. Nature communications 9 (1):5213

Lovell JT, Jenkins J, Lowry DB, Mamidi S, Sreedasyam A, Weng X, Barry K, Bonnette J, Campitelli B, Daum C (2018b) The genomic landscape of molecular responses to natural drought stress in Panicum hallii. Nature communications 9 (1):1-10

Lovell JT, Juenger TE, Michaels SD, Lasky JR, Platt A, Richards JH, Yu X, Easlon HM, Sen S, McKay JK (2013) Pleiotropy of FRIGIDA enhances the potential for multivariate adaptation. Proceedings of the Royal Society B: Biological Sciences 280 (1763):20131043

Lowry DB (2012) Ecotypes and the controversy over stages in the formation of new species. Biological Journal of the Linnean Society 106 (2):241-257

Lowry DB, Hernandez K, Taylor SH, Meyer E, Logan TL, Barry KW, Chapman JA, Rokhsar DS, Schmutz J, Juenger TE (2015) The genetics of divergence and reproductive isolation between ecotypes of Panicum hallii. New Phytologist 205 (1):402-414

Lowry DB, Lovell JT, Zhang L, Bonnette J, Fay PA, Mitchell RB, Lloyd-Reilley J, Boe AR, Wu Y, Rouquette FM (2019) QTLx environment interactions underlie adaptive divergence in switchgrass across a large latitudinal gradient. Proceedings of the National Academy of Sciences 116 (26):12933-12941

Lowry DB, Purmal CT, Juenger TE (2013) A population genetic transect of Panicum hallii (Poaceae). American Journal of Botany 100 (3):592-601

Lowry DB, Willis JH (2010a) A widespread chromosomal inversion polymorphism contributes to a major life-history transition, local adaptation, and reproductive isolation. PLoS biology 8 (9)

Lowry DB, Willis JH (2010b) A widespread chromosomal inversion polymorphism contributes to a major life-history transition, local adaptation, and reproductive isolation. PLoS Biol 8 (9):e1000500

Lu C, Shen L, He P, Chen Y, Zhu L, Tan Z, Xu Y (1997) Comparative mapping of QTLs for agronomic traits of rice across environments by using a doubled-haploid population. Theoretical and Applied Genetics $94(1): 145-150$

Lynch M, Walsh B (1998) Genetics and analysis of quantitative traits, vol 1. Sinauer Sunderland, MA, 
Marles MS, Ray H, Gruber MY (2003) New perspectives on proanthocyanidin biochemistry and molecular regulation. Phytochemistry 64 (2):367-383

Maughan P, Maroof MS, Buss G (1996) Molecular-marker analysis of seed-weight: genomic locations, gene action, and evidence for orthologous evolution among three legume species. Theoretical and Applied Genetics 93 (4):574-579

Meyer E, Aglyamova G, Matz MV (2011) Profiling gene expression responses of coral larvae (Acropora millepora) to elevated temperature and settlement inducers using a novel RNA-Seq procedure. Molecular ecology 20 (17):3599-3616

Mian M, Bailey M, Tamulonis J, Shipe E, Carter T, Parrott W, Ashley D, Hussey R, Boerma H (1996) Molecular markers associated with seed weight in two soybean populations. Theoretical and Applied Genetics 93 (7):1011-1016

Muller-Landau HC (2010) The tolerance-fecundity trade-off and the maintenance of diversity in seed size. Proceedings of the National Academy of Sciences 107 (9):4242-4247

Okamoto M, Kuwahara A, Seo M, Kushiro T, Asami T, Hirai N, Kamiya Y, Koshiba T, Nambara E (2006) CYP707A1 and CYP707A2, which encode abscisic acid 8'-hydroxylases, are indispensable for proper control of seed dormancy and germination in Arabidopsis. Plant physiology 141 (1):97-107

Orr HA (1998) Testing natural selection vs. genetic drift in phenotypic evolution using quantitative trait locus data. Genetics 149 (4):2099-2104

Palacio Mejia JD (2018) Ecology and evolution of cold tolerance in Panicum hallii.

Paterson AH, Lin Y-R, Li Z, Schertz KF, Doebley JF, Pinson SR, Liu S-C, Stansel JW, Irvine JE (1995) Convergent domestication of cereal crops by independent mutations at corresponding genetic loci. Science 269 (5231):1714-1718

Phillips PC, Arnold SJ (1999) Hierarchical comparison of genetic variance-covariance matrices. I. Using the Flury hierarchy. Evolution 53 (5):1506-1515

Primack RB, Antonovics J (1981) Experimental ecological genetics in Plantago. V. Components of seed yield in the ribwort plantain Plantago lanceolata L. Evolution:1069-1079

Prioul J-L, Quarrie S, Causse M, de Vienne D (1997) Dissecting complex physiological functions through the use of molecular quantitative genetics. Journal of Experimental Botany 48 (6):1151-1163

Rajakaruna N (2004) The edaphic factor in the origin of plant species. International Geology Review 46 (5):471-478

Rami J-F, Dufour P, Trouche G, Fliedel G, Mestres C, Davrieux F, Blanchard P, Hamon P (1998) Quantitative trait loci for grain quality, productivity, morphological and agronomical traits in sorghum (Sorghum bicolor L. Moench). Theoretical and applied genetics 97 (4):605-616

Rees M (1996) Evolutionary ecology of seed dormancy and seed size. Philos Trans R Soc Lond B Biol Sci 351 (1345):1299-1308

Rieseberg LH, Widmer A, Arntz AM, Burke JM (2002) Directional selection is the primary cause of phenotypic diversification. Proceedings of the National Academy of Sciences 99 (19):12242-12245

Roux F, Touzet P, Cuguen J, Le Corre V (2006) How to be early flowering: an evolutionary perspective. Trends in plant science 11 (8):375-381

Rundle HD, Nosil P (2005) Ecological speciation. Ecology letters 8 (3):336-352

Shipley B, Keddy P, Moore D, Lemky K (1989) Regeneration and establishment strategies of emergent macrophytes. The Journal of Ecology:1093-1110 
Silvertown J (1989) The paradox of seed size and adaptation. Trends in Ecology \& Evolution 4 (1):24-26

Smeins FE, Taylor TW, Merrill LB (1976) Vegetation of a 25-year exclosure on the Edwards Plateau, Texas. Rangeland Ecology \& Management/Journal of Range Management Archives 29 (1):24-29

Smith CC, Fretwell SD (1974) The optimal balance between size and number of offspring. The American Naturalist 108 (962):499-506

Stanton ML (1984) Developmental and genetic sources of seed weight variation in Raphanus raphanistrum L.(Brassicaceae). American Journal of Botany 71 (8):1090-1098

Stebbins Jr GL (1952) Aridity as a stimulus to plant evolution. The American Naturalist 86 (826):33-44

Sun S, Wang L, Mao H, Shao L, Li X, Xiao J, Ouyang Y, Zhang Q (2018) A G-protein pathway determines grain size in rice. Nature communications 9 (1):1-11

Timmerman-Vaughan G, McCallum J, Frew T, Weeden N, Russell A (1996) Linkage mapping of quantitative trait loci controlling seed weight in pea (Pisum sativum L.). Theoretical and Applied Genetics 93 (3):431-439

Venable DL (2007) Bet hedging in a guild of desert annuals. Ecology 88 (5):1086-1090

Waller FR (1976) A biosystematic study of Panicum section Diffusa (Poaceae) in North America. Waller,

Whittaker RH (1970) Communities and ecosystems. Communities and ecosystems

Woodward FI, Lomas MR, Kelly CK (2004) Global climate and the distribution of plant biomes. Philosophical Transactions of the Royal Society of London Series B: Biological Sciences 359 (1450):1465-1476

Wulff RD (1986) Seed size variation in Desmodium paniculatum: II. Effects on seedling growth and physiological performance. The Journal of Ecology:99-114

Xiao J, Li J, Grandillo S, Ahn SN, Yuan L, Tanksley SD, McCouch SR (1998) Identification of trait-improving quantitative trait loci alleles from a wild rice relative, Oryza rufipogon. Genetics 150 (2):899-909

Xiao J, Li J, Yuan L, Tanksley S (1996) Identification of QTLs affecting traits of agronomic importance in a recombinant inbred population derived from a subspecific rice cross. Theoretical and applied genetics 92 (2):230-244

\section{Figure and Table legends}

Table 1: Descriptive statistics for phenotypic traits forhallii and filipes parental lines and the recombinant inbred population $(\mathrm{SE}=$ standard error).

Table 2: Genomic positions and effects of the seed biology associated QTL identified in the RIL population. Main and epistatic effects of the identified QTLs have been listed here along with their maximum QTL LOD score, position on linkage map, percent of variance explained by each QTL, total variance explained by each QTL model for traits and the positive allele donor for each QTL.

Fig. 1: Seed and seedling size differences between P. hallii lowland and upland ecotypes. A) shows the representative differences in seed size between parental lines. This image was taken with 10 random seeds for both parental lines. B) shows seedling growth differences for these parental lines at 10 days from germination time. The upland ecotype grew larger than lowland ecotype in both belowground and above ground biomass. (C-D) show the effect of reciprocal transplantation on seed size and germination rate between parental lines. The differences between ecotypes were significant but the location does not affect seed mass or germination.

Fig. 2: Mean differences between hallii, filipesand RIL for all measured traits are presented as bar and whisker plots; red denotes hallii, blue denotes filipes and black denotes the RIL. Trait differences are statistically significant between parental lines (Supplementary File 8).

Fig. 3: The RIL genetic linkage map of Panicum halliigenerated from hallii $\mathrm{x}$ filipes mapping population. All identified QTL are presented as bars to the right of each linkage group. Each colored bar represents a 
QTL with length representing the 1.5-LOD drop confidence intervals. Black dots in the colored bars indicate the position of the QTL based on the maximum LOD score. GR = Germination Rate, RGR = Relative Growth Rate, RL10D = Root length at 10 days, $\mathrm{SA}=$ Seed Area, SL= Seed Length, SLen10D = Shoot Length at 10 days, SLen5D = Shoot Length at 5 days, $\mathrm{SM}=$ Seed Mass, SR $=$ Seed Roundness, SRR = Shoot Root Ratio at 10 days, SW = Seed Width and VI = Vigor Index.

Fig. 4: Epistatic interaction for germination time QTL and volcano plots showing gene e3xpression variation between parental lines. Fig A: pairwise epistatic QTL for Germination Time between Chromosome 6 and 9 in the P.hallii RIL population. Plotted points indicate two-locus genotype means \pm 1SE for the two loci containing germination time between Chr6 and Chr9. Fig B represents Volcano plots of significant genes differring between hallii and filipes seed tissue. The $\mathrm{x}$-axis represents fold change $(\mathrm{Fc})$ and the $\mathrm{y}$-axis represents negative $\log 10$ of the $\mathrm{P}$-value of each gene.

Fig 5: Seed viability and seed permeability test in parental lines. Fig A: seed viability test between hallii andfilipes. Ungerminated seeds were tested for germination by removing seed coat. The Y-axis corresponds to the percent of germinated seeds and the $\mathrm{X}$-axis provides the genotype information. Uplandhallii has a higher germination rate compared to filipesif seed coats are removed. Fig B shows the water permeability ofhallii and filipes seeds at 6 -time intervals. Y-axis shows the seed weight in $\mathrm{mg}$ and $\mathrm{X}$-axis shows the different times points. This plot clearly indicates that hallii has lower water permeability than filipes . Statistically significant differences between parental lines in specific time intervals has been marked asterisk: ${ }^{*} P<0.01$; **, $P<0.0001$.

Fig. 6: Correlation coefficients $(r)$ and their pairwise significance $(p)$ for seed mass, germination rate, shoot length and root length traits with RIL means. Seed mass showed an antagonistic relationship with germination rate and showed a positive relationship with both shoot length and root length traits.

\section{Table 1}

\begin{tabular}{|c|c|c|c|c|c|c|c|c|}
\hline Trait & $\mathbf{N}$ & $\begin{array}{l}\text { hallii } \\
\text { (mean } \pm \\
\text { SE) }\end{array}$ & $\mathbf{N}$ & $\begin{array}{l}\text { filipes } \\
\text { (mean } \pm \\
\mathrm{SE} \text { ) }\end{array}$ & $P$-value & $\mathbf{N}$ & $\begin{array}{l}\text { RIL } \\
\text { mean }\end{array}$ & $\begin{array}{l}\text { RIL } \\
\text { range }\end{array}$ \\
\hline $\begin{array}{l}\text { SM } \\
(\mathrm{mg})\end{array}$ & 13 & $\begin{array}{l}1.29 \\
\pm 0.01\end{array}$ & 15 & $0.57 \pm 0.01$ & $<.0001$ & 293 & 0.91 & $\begin{array}{l}0.38- \\
1.56\end{array}$ \\
\hline $\mathrm{SL}(\mathrm{mm})$ & 13 & $1.91 \pm 0.02$ & 15 & $1.62 \pm 0.02$ & $<.0001$ & 290 & 1.75 & $\begin{array}{l}1.46- \\
2.21\end{array}$ \\
\hline $\begin{array}{l}\text { SW } \\
(\mathrm{mm})\end{array}$ & 13 & $1.25 \pm 0.01$ & 15 & $0.92 \pm 0.01$ & $<.0001$ & 290 & 1.07 & $\begin{array}{l}0.90- \\
1.26\end{array}$ \\
\hline $\begin{array}{l}\mathrm{SA} \\
\left(\mathrm{mm}^{2}\right)\end{array}$ & 13 & $2.13 \pm 0.10$ & 15 & $1.37 \pm 0.07$ & $<.0001$ & 290 & 1.50 & $\begin{array}{l}1.02- \\
2.73\end{array}$ \\
\hline $\begin{array}{l}\text { SR } \\
(\mathrm{mm})\end{array}$ & 13 & $0.65 \pm 0.01$ & 15 & $0.57 \pm 0.01$ & .0002 & 290 & 0.61 & $\begin{array}{l}0.49- \\
0.74\end{array}$ \\
\hline $\begin{array}{l}\text { GR } \\
(\%)\end{array}$ & 13 & $31.2 \pm 2.39$ & 15 & $86.21 \pm 2.23$ & $<.0001$ & 278 & 55.38 & $\begin{array}{l}6.61- \\
98.37\end{array}$ \\
\hline SL5(mm) & 13 & $12.57 \pm 0.43$ & 15 & $11.27 \pm 0.40$ & 0.0373 & 278 & 14.40 & $\begin{array}{l}4.61- \\
21.94\end{array}$ \\
\hline SL10(mm) & 13 & $23.8 \pm 0.82$ & 15 & $18.04 \pm 0.70$ & $<.0001$ & 278 & 22.04 & $\begin{array}{l}12.66- \\
31.33\end{array}$ \\
\hline RL10(mm) & 13 & $41.75 \pm 1.47$ & 15 & $11.14 \pm 1.37$ & $<.0001$ & 278 & 16.62 & $\begin{array}{l}6.13- \\
59.80\end{array}$ \\
\hline $\begin{array}{l}\text { SRR } \\
(\mathrm{mm})\end{array}$ & 13 & $0.57 \pm 0.01$ & 15 & $1.71 \pm 0.09$ & $<.0001$ & 278 & 1.66 & $\begin{array}{l}0.46- \\
4.36\end{array}$ \\
\hline $\begin{array}{l}\text { GT } \\
\text { (hrs) }\end{array}$ & 13 & $\begin{array}{l}92.3 \pm \\
2.8\end{array}$ & 15 & $30.4 \pm 2.61$ & $<.0001$ & 278 & 74.22 & $36-240$ \\
\hline
\end{tabular}




\begin{tabular}{|c|c|c|c|c|c|c|c|c|c|}
\hline Trait & $\mathbf{N}$ & $\begin{array}{l}\text { hallii } \\
\text { (mean } \pm \\
\text { SE) }\end{array}$ & $\mathbf{N}$ & $\begin{array}{l}\text { filipes } \\
\text { (mean } \pm \\
\text { SE) }\end{array}$ & P-value & $\mathbf{N}$ & $\begin{array}{l}\text { RIL } \\
\text { mean }\end{array}$ & $\begin{array}{l}\text { RIL } \\
\text { range }\end{array}$ & $\mathbf{H}$ \\
\hline RGR & 13 & $2.24 \pm 0.13$ & 15 & $1.35 \pm 0.12$ & $<.0001$ & 278 & 1.54 & $\begin{array}{l}0.48- \\
3.55\end{array}$ & $\begin{array}{l}0 . \\
0 .\end{array}$ \\
\hline VI & 13 & $745.95 \pm 81$ & 215 & $1564.5 \pm 76$ & $8<.0001$ & 278 & 1234.1 & $\begin{array}{l}92.85- \\
2549.85\end{array}$ & $\begin{array}{l}0 . \\
0 .\end{array}$ \\
\hline
\end{tabular}

Table 2

\begin{tabular}{|c|c|c|c|c|c|c|c|c|c|c|}
\hline Trait & Chr & $\begin{array}{l}\text { Pos } \\
\text { (cM) }\end{array}$ & $\begin{array}{l}\text { LOD } \\
\text { Peak }\end{array}$ & $\begin{array}{l}\text { 1.5- } \\
\text { LOD } \\
\text { Inter- } \\
\text { val }\end{array}$ & $\% \operatorname{Var}$ & Effect & SE & $\begin{array}{l}\% \\
\text { model } \\
\text { varia- } \\
\text { tion }\end{array}$ & Donor & $\begin{array}{l}\text { No of } \\
\text { Genes } \\
\text { in QTL } \\
\text { Inter- } \\
\text { vals }\end{array}$ \\
\hline SM & 1 & 97.7 & 3.50 & $\begin{array}{l}48- \\
123\end{array}$ & 3.9 & 0.030 & 0.007 & 31.90 & hallii & 2370 \\
\hline SM & 2 & 85.3 & 6.00 & $82-96$ & 6.7 & 0.041 & 0.007 & & hallii & 391 \\
\hline SM & 3 & 86.3 & 4.73 & $22-92$ & 5.3 & 0.036 & 0.007 & & hallii & 2403 \\
\hline $\mathrm{SM}$ & 5 & 138.6 & 4.50 & $\begin{array}{l}129- \\
142\end{array}$ & 5.0 & 0.038 & 0.008 & & hallii & 524 \\
\hline SM & 7 & 71.3 & 5.79 & $61-82$ & 6.5 & 0.040 & 0.007 & & hallii & 804 \\
\hline $\mathrm{SL}$ & 1 & 118.1 & 8.92 & $\begin{array}{l}114- \\
123\end{array}$ & 9.0 & 0.039 & 0.005 & 40.81 & hallii & 365 \\
\hline SL & 4 & 13.4 & 8.42 & $9-17$ & 8.5 & 0.037 & 0.005 & & hallii & 133 \\
\hline SL & 7 & 65.3 & 5.28 & $58-76$ & 5.2 & 0.027 & 0.005 & & hallii & 576 \\
\hline SL & 9 & 154.4 & 9.2 & $\begin{array}{l}152- \\
164\end{array}$ & 9.3 & 0.037 & 0.005 & & hallii & 421 \\
\hline SW & 1 & 52.4 & 3.98 & $48-62$ & 3.6 & 0.013 & 0.003 & 44.24 & hallii & 498 \\
\hline SW & 1 & 6.3 & 4.04 & $0-17$ & 3.7 & 0.013 & 0.003 & & hallii & 636 \\
\hline SW & 2 & 92.3 & 7.44 & $82-94$ & 6.9 & 0.019 & 0.003 & & hallii & 339 \\
\hline SW & 3 & 86.3 & 10.41 & $84-89$ & 10.0 & 0.022 & 0.003 & & hallii & 85 \\
\hline SW & 4 & 4.4 & 4.84 & $0-13$ & 4.5 & 0.015 & 0.003 & & hallii & 444 \\
\hline SW & 5 & 130.1 & 4.13 & $\begin{array}{l}126- \\
134\end{array}$ & 3.8 & 0.015 & 0.003 & & hallii & 294 \\
\hline SA & 3 & 89.9 & 5.31 & 79-92 & 6.7 & 0.068 & 0.013 & 24.29 & hallii & 290 \\
\hline SA & 4 & 2.8 & 6.83 & $1-12$ & 8.7 & 0.078 & 0.013 & & hallii & 340 \\
\hline SA & 9 & 154.5 & 6.17 & $\begin{array}{l}140- \\
159\end{array}$ & 7.8 & 0.072 & 0.013 & & hallii & 523 \\
\hline SR & 1 & 109.1 & 6.89 & $\begin{array}{l}104- \\
111\end{array}$ & 6.9 & -0.012 & 0.002 & 32.34 & filipes & 323 \\
\hline SR & 1 & 4.8 & 7.07 & $2-11$ & 7.1 & 0.012 & 0.002 & & hallii & 343 \\
\hline SR & 1 & 54.7 & 4.93 & $50-63$ & 4.9 & 0.010 & 0.002 & & hallii & 286 \\
\hline SR & 3 & 99.1 & 9.41 & $\begin{array}{l}95- \\
101\end{array}$ & 9.6 & 0.014 & 0.002 & & hallii & 616 \\
\hline SR & 5 & 13.3 & 4.91 & $7-19$ & 4.8 & 0.010 & 0.002 & & hallii & 354 \\
\hline SR & 9 & 163.6 & 4.4 & $\begin{array}{l}80- \\
164\end{array}$ & 4.4 & -0.009 & 0.002 & & filipes & 2810 \\
\hline GR & 2 & 26.3 & 3.1 & $20-36$ & 3.4 & -3.828 & 1.010 & 36.05 & filipes & 344 \\
\hline GR & 2 & 83.9 & 8.11 & $81-85$ & 9.2 & -6.389 & 1.021 & & filipes & 92 \\
\hline
\end{tabular}




\begin{tabular}{|c|c|c|c|c|c|c|c|c|c|c|}
\hline Trait & Chr & $\begin{array}{l}\text { Pos } \\
\text { (cM) }\end{array}$ & $\begin{array}{l}\text { LOD } \\
\text { Peak }\end{array}$ & $\begin{array}{l}\text { 1.5- } \\
\text { LOD } \\
\text { Inter- } \\
\text { val }\end{array}$ & $\% \operatorname{Var}$ & Effect & SE & $\begin{array}{l}\% \\
\text { model } \\
\text { varia- } \\
\text { tion }\end{array}$ & Donor & $\begin{array}{l}\text { No of } \\
\text { Genes } \\
\text { in QTL } \\
\text { Inter- } \\
\text { vals }\end{array}$ \\
\hline$\overline{\mathrm{GR}}$ & 3 & 118.9 & 4.72 & $\begin{array}{l}108- \\
125\end{array}$ & 5.21 & -4.647 & 0.987 & & filipes & 239 \\
\hline GR & 5 & 136 & 3.80 & $\begin{array}{l}130- \\
138\end{array}$ & 4.1 & -4.827 & 1.148 & & filipes & 222 \\
\hline GR & 9 & 128.1 & 6.46 & $\begin{array}{l}121- \\
129\end{array}$ & 7.2 & -6.329 & 1.142 & & filipes & 296 \\
\hline SL5 & 1 & 108 & 3.93 & $\begin{array}{l}100- \\
118\end{array}$ & 4.9 & -0.670 & 0.156 & 26.45 & filipes & 562 \\
\hline SL5 & 1 & 25.7 & 4.75 & $21-28$ & 6.0 & -0.715 & 0.151 & & filipes & 127 \\
\hline SL5 & 2 & 131.8 & 4.22 & $\begin{array}{l}122- \\
143\end{array}$ & 5.3 & 0.678 & 0.152 & & hallii & 613 \\
\hline SL5 & 4 & 47.1 & 4.11 & $42-61$ & 5.2 & 1.702 & 0.160 & & hallii & 833 \\
\hline SL5 & 7 & 82.9 & 5.23 & $66-82$ & 6.6 & 0.772 & 0.155 & & hallii & 667 \\
\hline SL10 & 2 & 126 & 6.19 & $\begin{array}{l}120- \\
134\end{array}$ & 9.7 & 0.073 & 0.013 & 9.75 & hallii & 330 \\
\hline RL10D & 3 & 11.7 & 3.82 & $10-21$ & 6.1 & 0.152 & 0.036 & 6.13 & hallii & 406 \\
\hline GT & 6 & 50 & 7.64 & $44-53$ & 11.5 & -0.797 & 0.161 & 15.19 & filipes & 253 \\
\hline GT & Epi6:9 & NA & 7.46 & NA & 11.1 & -0.983 & 0.163 & & NA & NA \\
\hline GT & 9 & 121.3 & 9.90 & $\begin{array}{l}116- \\
125\end{array}$ & 15.1 & 0.928 & 0.156 & & hallii & 524 \\
\hline VI & 2 & 83.9 & 5.06 & $78-86$ & 6.1 & $\begin{array}{l}- \\
125.656\end{array}$ & 25.76 & 29.75 & filipes & 240 \\
\hline VI & 3 & 120.0 & 5.56 & $\begin{array}{l}108- \\
125\end{array}$ & 6.8 & $\begin{array}{l}- \\
129.314\end{array}$ & 25.245 & & filipes & 239 \\
\hline VI & 8 & 13.6 & 3.49 & $9-18$ & 4.1 & 102.287 & 25.421 & & hallii & 157 \\
\hline VI & 8 & 49.2 & 4.35 & $44-53$ & 5.2 & $\begin{array}{l}- \\
111.95\end{array}$ & 24.845 & & filipes & 151 \\
\hline VI & 9 & 128.1 & 6.13 & $\begin{array}{l}120- \\
129\end{array}$ & 7.5 & -153.2 & 28.405 & & filipes & 533 \\
\hline SRR & 3 & 11.7 & 4.04 & $10-21$ & 6.8 & -0.174 & 0.039 & 6.48 & filipes & 406 \\
\hline
\end{tabular}

Chr, linkage group; Pos (cM), Centimorgan position of the QTL peak; LOD, logarithm of odds; 1.5-LOD Interval, confidence interval at 1.5 LOD drop; \% Var, percent of variance explained by each QTL; SE, standard error for each identified QTL; Effect, QTL effects; \% model var, percent of variance explained by each QTL model for traits; Donor, positive allele donor for identified QTLs; QTL Genes, Number of genes from each QTL confidence intervals; Epi, Epistasis.

Figure 1 

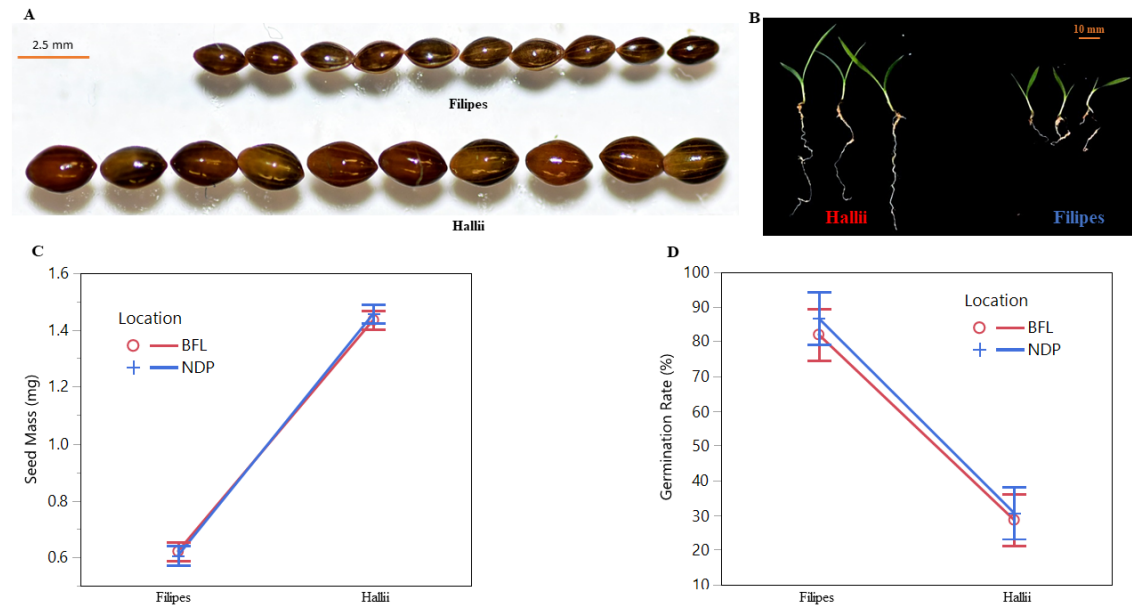

Figure 2

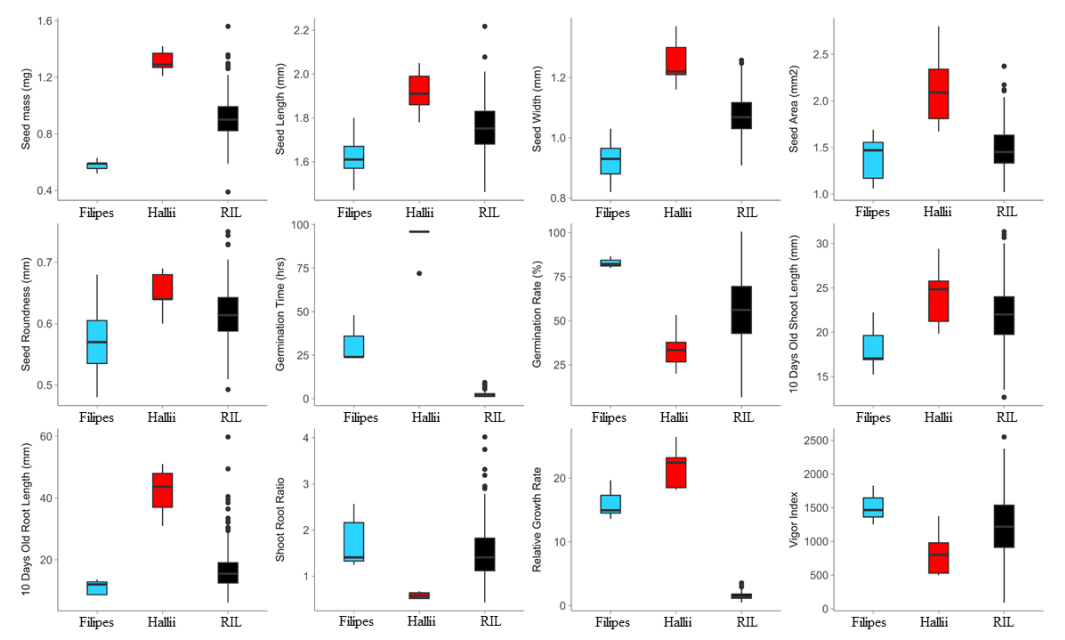

Figure 3 


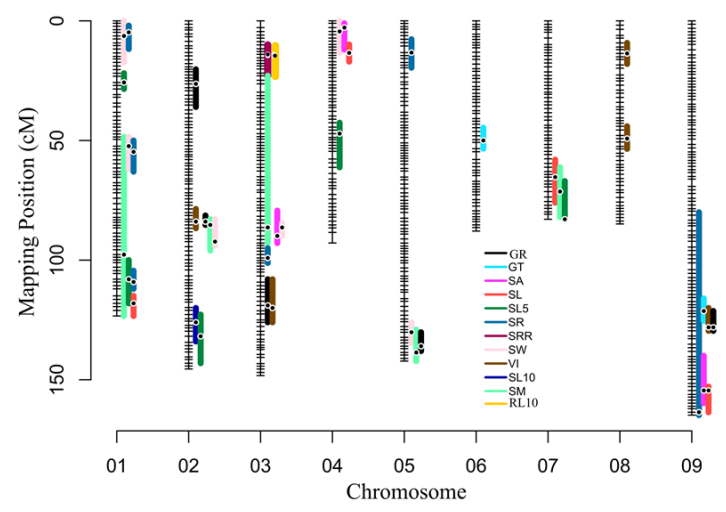

Figure 4
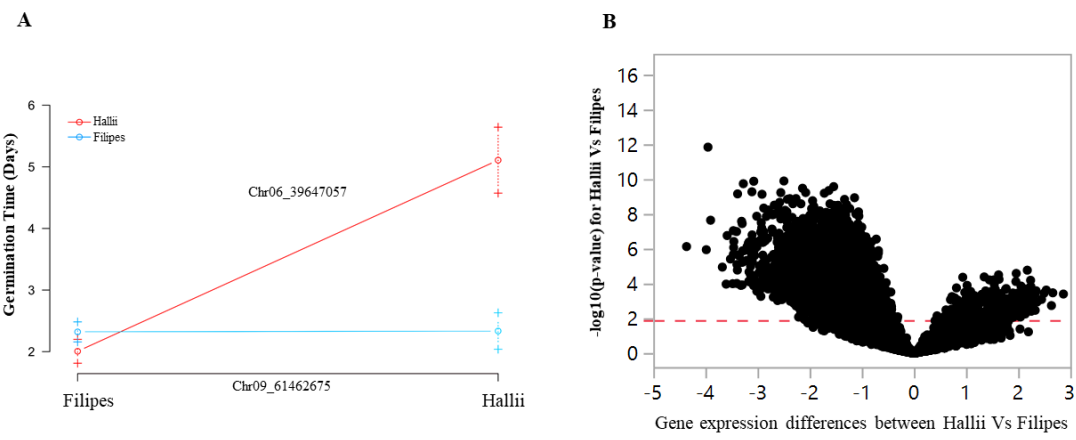

Figure 5 

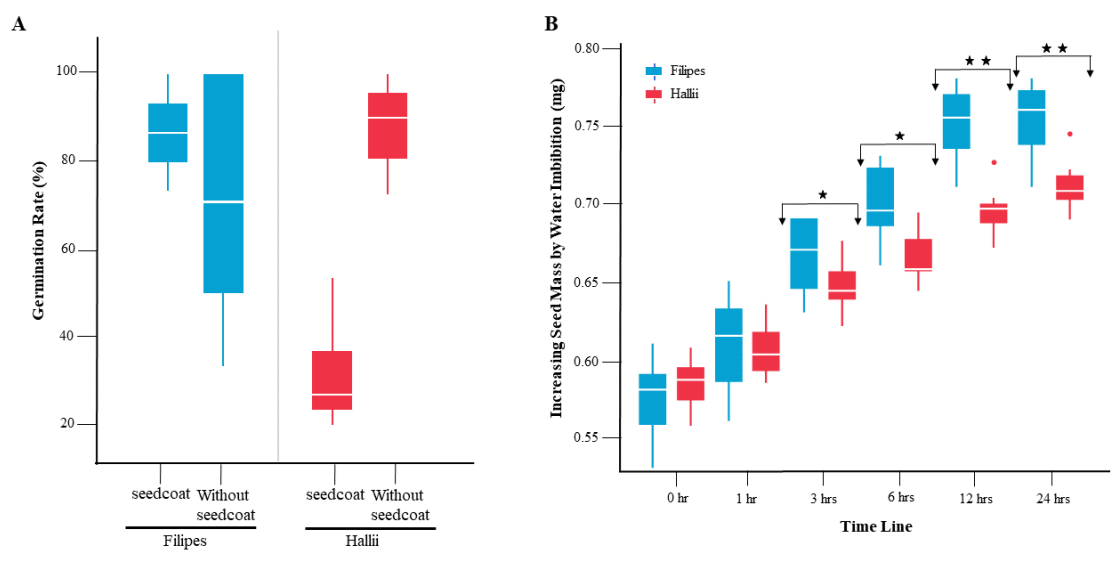

Figure 6
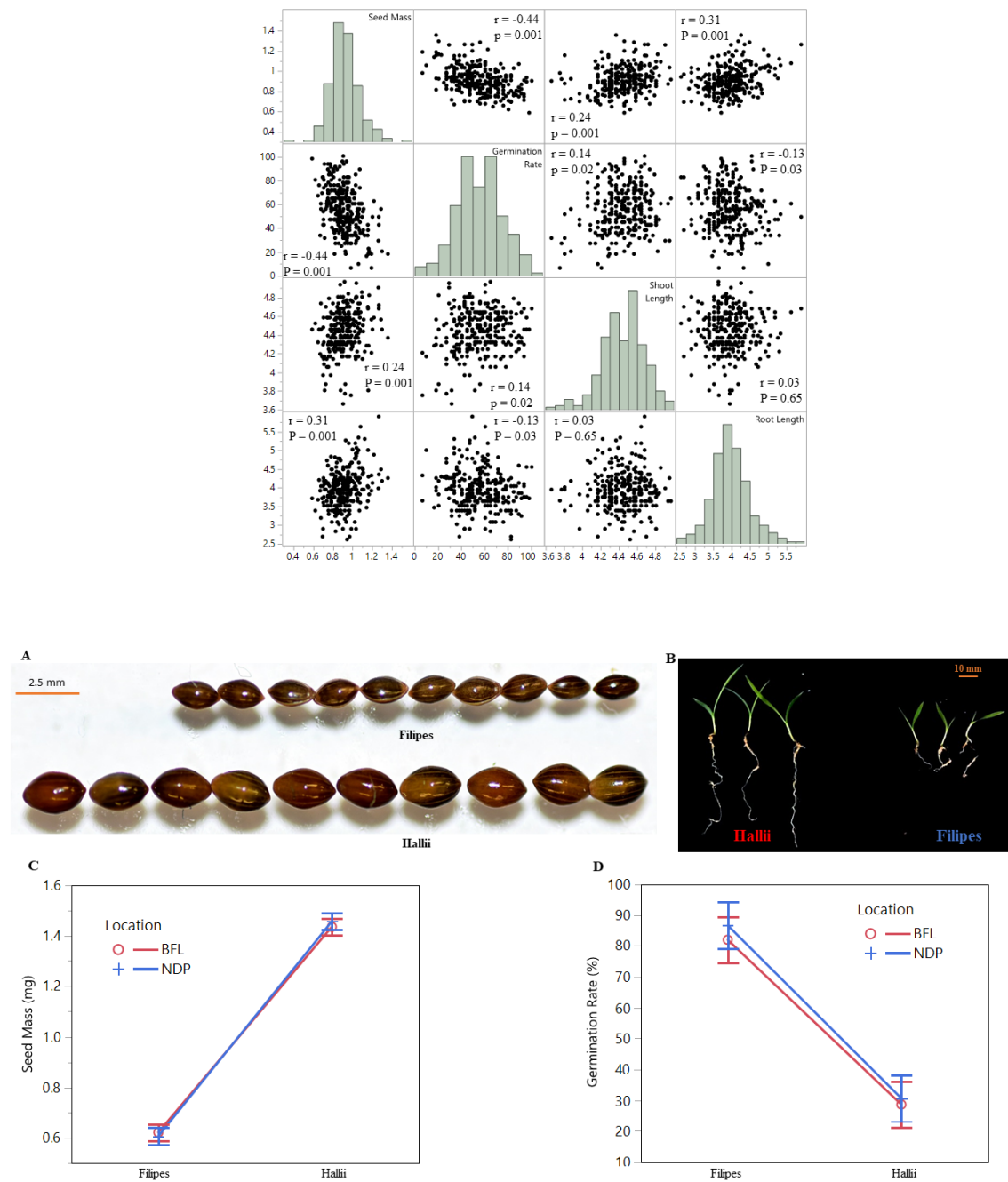

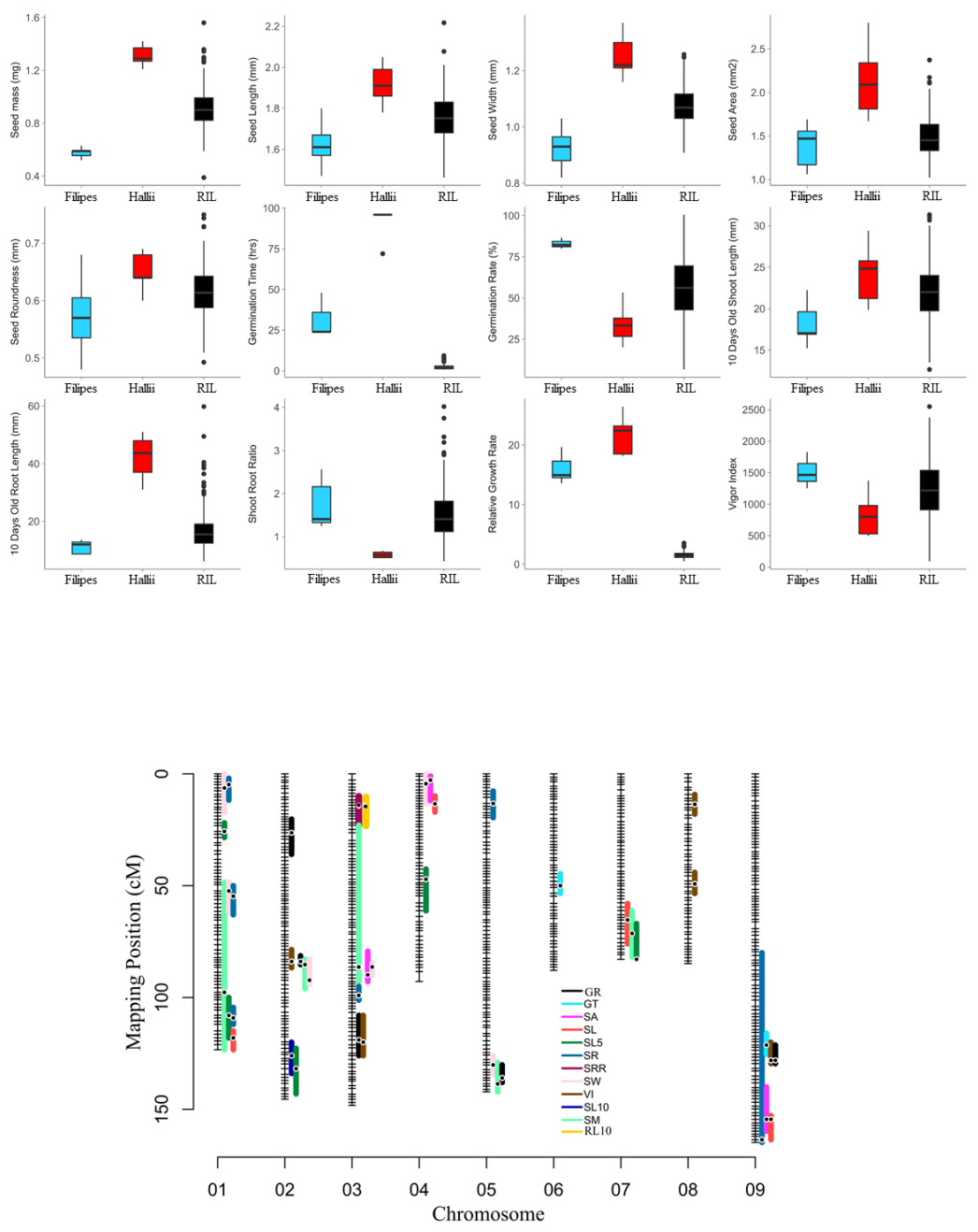

A

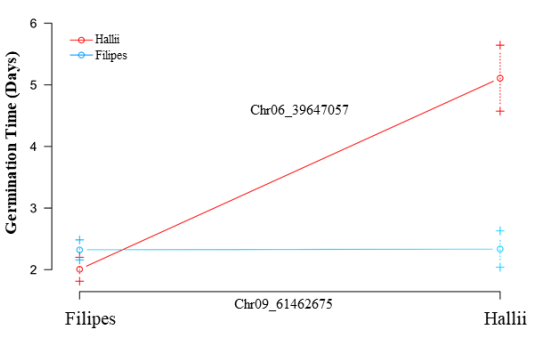

B

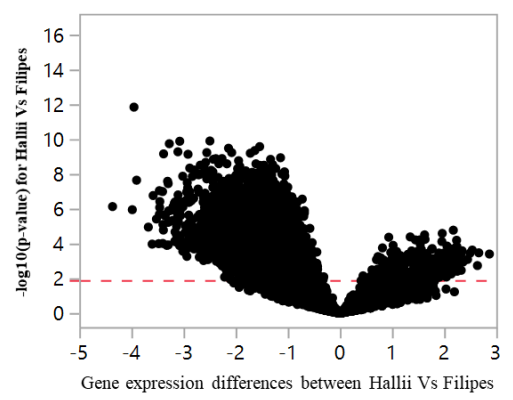

25 

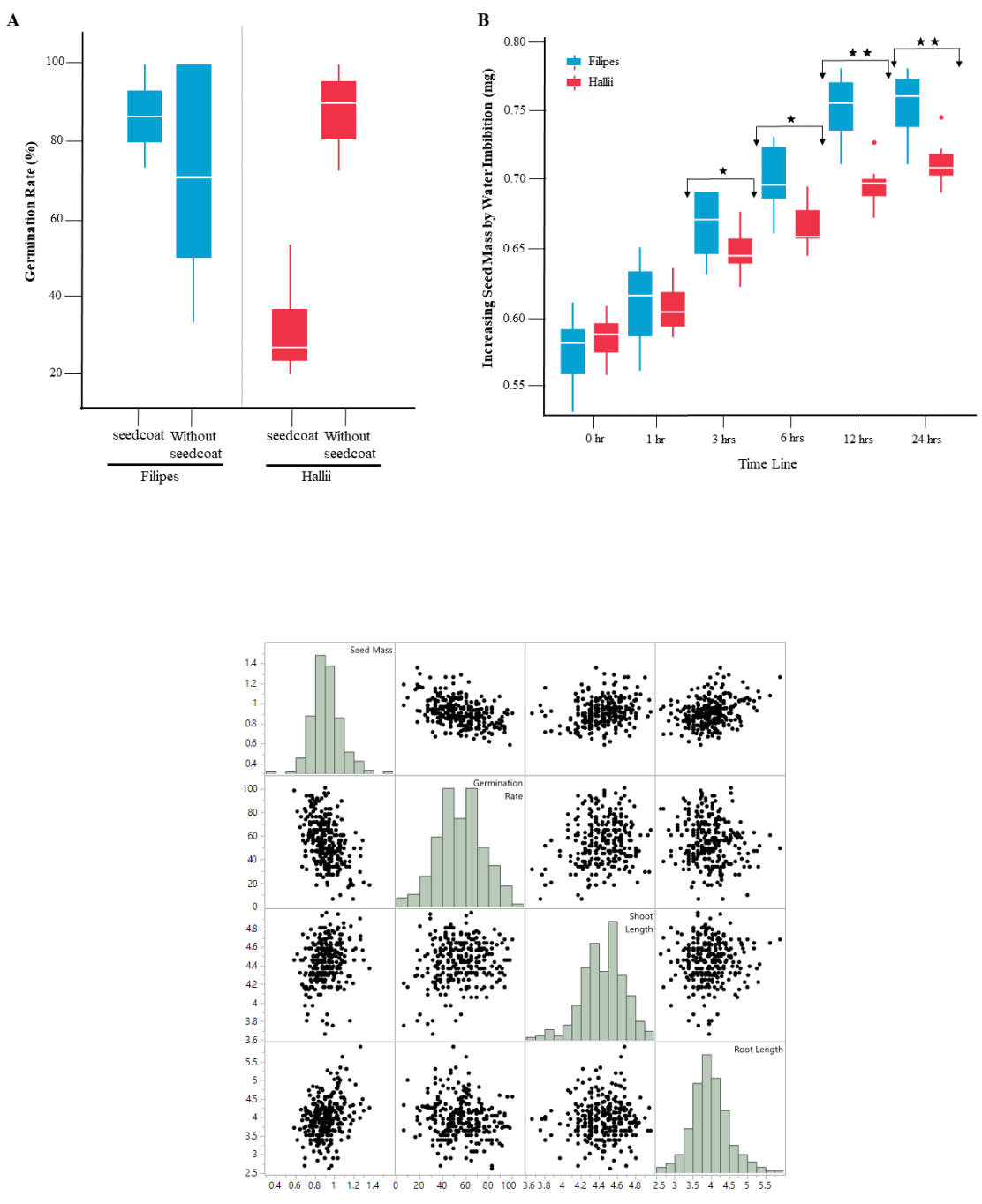